\title{
On the onset of bora and the formation of rotors and jumps near a mountain gap
}

\author{
Alexander Gohm, ${ }^{a *}$ Georg J. Mayr, ${ }^{\mathrm{a}}$ Andreas Fix ${ }^{\mathrm{b}}$ and Andreas Giez ${ }^{\mathrm{b}}$ \\ a University of Innsbruck, Austria \\ b DLR Oberpfaffenhofen, Germany
}

\begin{abstract}
This study investigates the onset phase of a strong Adriatic bora windstorm that occurred on 4 April 2002. The target area is a gap about $20 \mathrm{~km}$ wide embedded in the coastal mountain barrier of the Dinaric Alps that favours strong jet-like winds. Airborne-aerosol back-scatter lidar measurements on board the DLR Falcon research aircraft, together with surface and upper-air observations, are used to verify high-resolution numerical experiments conducted with the mesoscale atmospheric model RAMS and a single-layer shallow-water model (SWM). Especially during the breakthrough phase of the bora, the flow at the gap exit exhibits a complex spatial structure and temporal evolution. On a transect through the centre of the gap, a hydraulic jump forms; this is located close to the coast throughout the night, and starts to propagate downstream in the early morning. On a transect through the edge of the gap, a lee-wave-induced rotor becomes established, due to boundary-layer separation. It starts to propagate downstream about two hours after the jump. This flow evolution implies that the onset of strong winds at the coast occurs several hours earlier downstream of the centre of the gap than downwind of the edge of the gap. Consequently, the wind field in the vicinity of Rijeka airport, located downwind of the gap, is strongly inhomogeneous and transient, and represents a potential hazard to aviation. Measured bora winds at the surface exceed $20 \mathrm{~ms}^{-1}$, and the simulated wind speed in the gap wind layer exceeds $30 \mathrm{~ms}^{-1}$. The simulated turbulent kinetic energy exceeds $10 \mathrm{~m}^{2} \mathrm{~s}^{-2}$.

RAMS indicates that wave-breaking near a critical level is the dominant mechanism for the generation of the windstorm. Gap jets can be identified downstream of several mountain passes. The simulated wave pattern above the Dinaric Alps, the wave decay with height due to directional wind shear and the strong flow descent on the leeward side of the barrier are supported by measured back-scatter intensities. Basic bora flow features, including gap jets and jumps, are remarkably well reproduced by SWM simulations. The RAMS reference run captures observed flow phenomena and the temporal flow evolution qualitatively well. A cold low-level bias, an overestimated bora inversion strength, and a slightly too-early bora onset are probably related to insufficient turbulent mixing in the boundary layer. The amplitude of trapped gravity waves, the time of the bora breakthrough and the inversion strength are found to be quite sensitive to the turbulence parametrization. Copyright (c) 2008 Royal Meteorological Society
\end{abstract}

KEY WORDS downslope windstorm; gap winds; lee waves; numerical modelling; airborne lidar

Received 22 May 2007; Revised 30 November 2007; Accepted 5 December 2007

\section{Introduction}

Mountain-induced downslope windstorms are accompanied by a multitude of atmospheric phenomena. Many of these are associated with strong turbulence, and represent potential hazards to air, ground and sea transportation, and more generally to the population in mountainous regions. Related phenomena include breaking gravity waves, hydraulic jumps, atmospheric rotors, gap jets, boundary-layer separation, flow splitting, and nonstationary flow behaviour. Recent field campaigns have specifically addressed some of these issues for several different topographic environments (e.g. Mobbs et al., 2005; Mayr et al., 2007; Drobinski et al., 2007; Grubišić et al., 2008). The present case study is a contribution to

* Correspondence to: Alexander Gohm, Institute of Meteorology and Geophysics, University of Innsbruck, Innrain 52, A-6020 Innsbruck, Austria. E-mail: alexander.gohm@uibk.ac.at this field of research, with specific regard to the Adriatic bora windstorm that occurs on the leeward side of the Dinaric Alps. We focus on the complex, evolving flow structure in the vicinity of a mountain gap during the onset phase of a bora event. We will show that this early stage is characterized by non-stationary jumps and rotors.

The demand for improved knowledge of these winds is motivated by their impact on aviation safety (e.g. Carney et al., 1996) and their role in air-sea interactions and sediment and biological transports (e.g. Lee et al., 2005). Most of the ALPEX (Alpine Experiment (WMO/ICSU)) bora studies of the last century have treated the bora as a quasi-two-dimensional flow across an elongated ridge, and have explained observed flow behaviour in terms of two-dimensional hydraulic and gravity-wave theories (e.g. Smith, 1987; Klemp and Durran, 1987; Grubišić, 1989; Jurčec and Glasnović, 1991; Bajić, 1991). Recent 
investigations conducted since the Mesoscale Alpine Programme (MAP) have focused more specifically on three-dimensional and small-scale aspects of bora winds: the role of mountain gaps in the formation of shear lines and potential-vorticity banners (Grubišić, 2004); the influence of gravity-wave breaking on the formation of surface wakes and jets (Jiang and Doyle, 2005); the role of boundary-layer separation in the development of gap winds (Gohm and Mayr, 2005); the dynamics and predictability of bora turbulence and gusts (Belušić and Klaić, 2004; Belušić et al., 2004; Belušić and Klaić, 2006); the sensitivity of bora winds to the sea-surface temperature (Cesini et al., 2004; Kraljević and Grisogono, 2006); and the impact of the bora flow on ocean currents and air-sea interactions (Pullen et al., 2003; Pullen et al., 2006; Pullen et al., 2007; Dorman et al., 2006; Kuzmić et al., 2006).

Studies of mountain lee waves and associated turbulent phenomena are of special interest in this work. Motivated by early results of the Sierra Wave Project (see Grubišić and Lewis (2004)), research on mountain-wave-induced rotors has experienced a renaissance in the new millennium. Using two-dimensional numerical simulations, Doyle and Durran (2002) showed that the formation of low-level rotors underneath trapped gravity waves is a result of boundary-layer separation that is greatly facilitated by the adverse, lee-wave-induced pressure gradient. They also showed that surface friction is crucial for the formation of rotors in general, as no rotors are observed in an idealized free-slip case. Shear production appears to be the dominant source for turbulent kinetic energy (TKE) in the rotor, although buoyancy production through surface heating may significantly increase TKE. In a later study, Doyle and Durran (2007) focused on the internal structure of rotors. They found that shear instability at the upstream edge of the main rotor leads to the formation of sub-rotors. These sub-rotors are stronger in three-dimensional than in two-dimensional simulations, and are further intensified by vortex stretching and tilting in the case of irregular topography. Using idealized two-dimensional numerical experiments, Hertenstein and Kuettner (2005) identified two types of rotors that may occur depending on the type and strength of shear in an elevated inversion. The first type forms underneath a resonant mountain wave, and exhibits a well-defined circulation. The second type is much more severe with respect to turbulence, and shows characteristics of a hydraulic jump. A recent series of papers focus on the identification of parameters that predict the occurrence of flow separation beneath lee waves and the formation of rotors (Vosper, 2004; Vosper et al., 2006; Sheridan and Vosper, 2006a; Jiang et al., 2007).

Several observational and numerical case studies provide evidence for the actual occurrence of lee-waveinduced rotors, and refer to the potential hazard that they may represent to aviation. Ralph et al. (1997) and Darby and Poulos (2006) observed rotor circulations on the leeward side of the Rocky Mountains with a Dopplerwind lidar. Mobbs et al. (2005) analysed data from a dense network of automatic weather stations on the Falkland Islands. Following ideas of Vosper (2004), they constructed a regime diagram, and identified three flow regimes: strong and weak downwind acceleration, and strong acceleration combined with high spatial-flow variability associated with flow separation and presumably rotor formation. The occurrence of rotors in this target area was later supported by the work of Sheridan and Vosper (2006a, 2006b) based on three-dimensional numerical simulations.

In our present target area, the Dinaric Alps, atmospheric rotors in conjunction with bora winds were first documented over a hundred years ago by Andrija Mohorovičić, who used cloud observations (see Grubišić and Orlić (2007)). However, since then, rotors have not been a feature of bora research. This leads us to the main objective of our present study: we want to elucidate the highly transient and three-dimensional flow field in the vicinity of an airport downwind of a mountain gap during the breakthrough phase of a bora windstorm. We will show that the gap flow is non-uniform in the cross-stream direction, and features hydraulic jumps alongside rotors. This study complements the results of Gohm and Mayr (2005), who focused on an event with a different type of synoptic background flow and hence a different type of gravity-wave forcing.

In Section 2 we describe the numerical models and the observations used in this study. Section 3 provides a synoptic and mesoscale overview of the event, and illustrates the bora evolution observed at the surface. In Section 4, numerical simulations are compared with observations. The phenomena of a wave-induced rotor and a hydraulic jump are examined in Section 5. Section 6 discusses the sensitivity of the numerical experiments to the turbulence parametrization. We conclude with a summary in Section 7.

\section{Models and measurements}

\subsection{The mesoscale model RAMS}

The three-dimensional numerical simulations in this study are performed with the Regional Atmospheric Modelling System (RAMS) version 4.4 (Pielke et al., 1992; Cotton et al., 2003). This model solves the nonhydrostatic primitive equations using a finite-difference method on a polar-stereographic projection in the horizontal directions and on a terrain-following coordinate in the vertical direction.

Except as indicated otherwise, the model set-up is essentially the same as in Gohm and Mayr (2005). We apply a two-way interactive grid-nesting technique with six nested model grids. The horizontal mesh sizes of these six domains are approximately $64.8 \mathrm{~km}$, $21.6 \mathrm{~km}, 7.2 \mathrm{~km}, 2.4 \mathrm{~km}, 800 \mathrm{~m}$ and $267 \mathrm{~m}$. The coarsest domain (grid 1) covers most of Europe. The locations of grids 2-3 and 4-6 are shown in Figure 1(a) and (c) respectively. Most of the results presented herein are 
(a)

ECMWF Analysis, Geopot. Height (m) at $300 \mathrm{hPa}, 04-\mathrm{Apr}-200206$ UTC

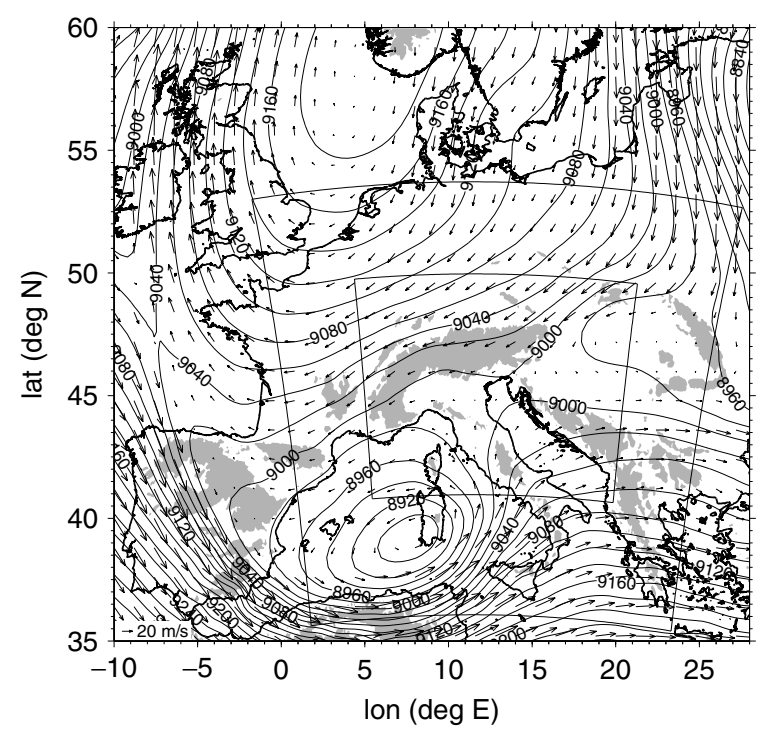

(c)

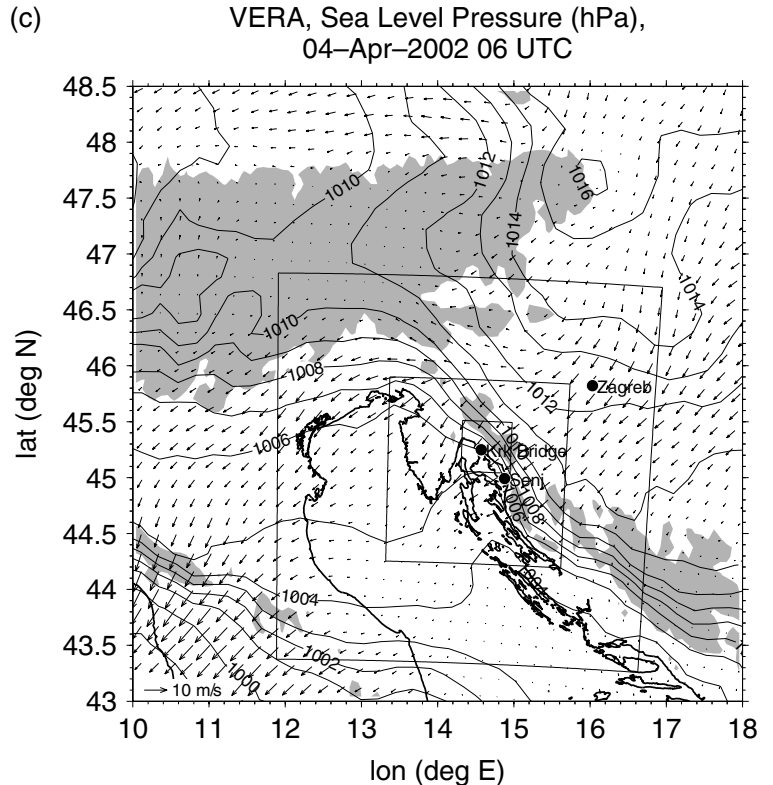

(b)

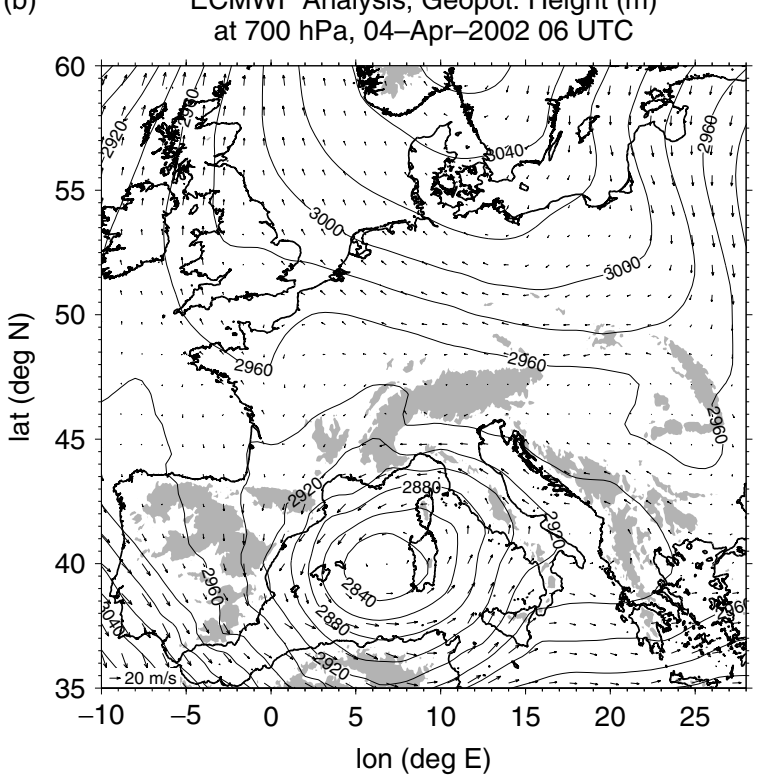

(d)

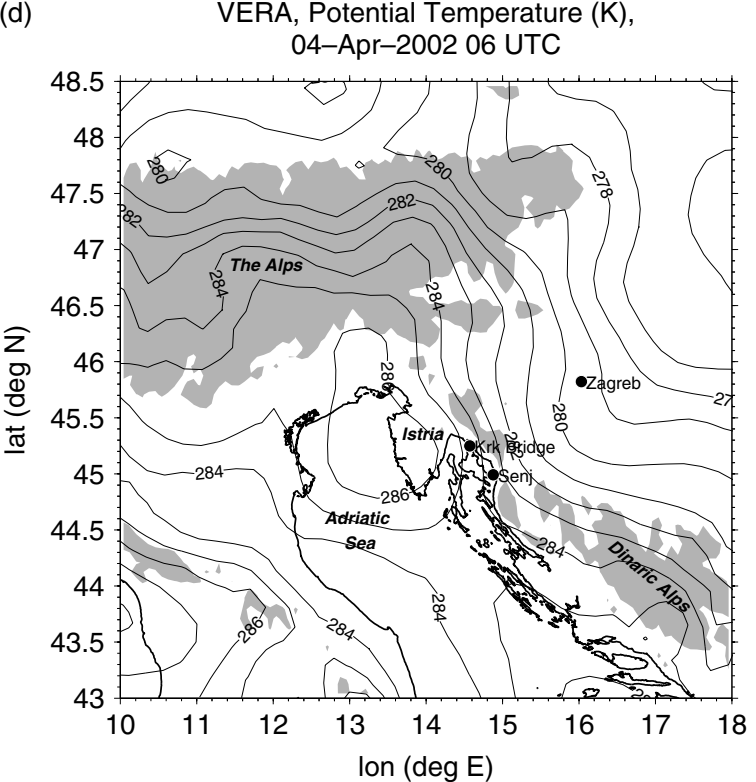

Figure 1. Analysis for $06 \mathrm{UTC}$ on 4 April 2002. ECMWF field of geopotential height at (a) $300 \mathrm{hPa}$ and (b) $700 \mathrm{hPa}$, with horizontal wind vectors (see lower-left corner for reference vector). The contour interval is $20 \mathrm{~m}$. VERA fields of (c) sea-level pressure with horizontal wind vectors and (d) surface potential temperature. The contour intervals are $1 \mathrm{hPa}$ and $1 \mathrm{~K}$ respectively. The $800 \mathrm{~m}$-elevation contour of the topography is shown by grey shading. The boxes in (a) indicate RAMS model domains 2 and 3, and those in (c) indicate domains 4, 5 and 6. Model domain 1 exceeds the total region shown in (a).

taken from grids 5 and 6 . The former covers the northern part of the Dinaric Alps (Figure 2), and the latter (in contrast to Gohm and Mayr (2005)) the mountain gap Delnička Vrata, which represents the main target area of our study (see subdomain of Figure 2(a)). The vertical domain is discretized into 56 unevenly-spaced levels with a grid spacing of about $30 \mathrm{~m}$ at the surface, increasing smoothly to a maximum of $500 \mathrm{~m}$ at about $3 \mathrm{~km}$ above mean sea level (AMSL). From there on, the mesh size is kept constant up to the model top, located at $20.6 \mathrm{~km}$ AMSL. Model data henceforth referred to as 'surface' or 'near-surface' data are taken from about $15 \mathrm{~m}$ above ground level (AGL), except for the grid point at Krk Bridge where data from about $47 \mathrm{~m}$ AGL are used. A viscous layer is applied above $15 \mathrm{~km}$ AMSL in order to dampen upward-propagating gravity waves. Initial and boundary conditions are provided by threehourly ECMWF analyses (see Gohm and Mayr (2005) for details). The model is initialized at 18 UTC on 3 April 2002. The spin-up time of the model for the generation of a realistic gravity-wave field is estimated to be less than three hours.

RAMS uses a full package of parametrizations for representing cloud microphysics, convection (applied in grids 1-2), and radiation (see Gohm and Mayr (2005)). Vertical turbulent fluxes of heat, moisture and momentum 
(a)

$$
\begin{aligned}
\text { RAMS } & \text { 04-Apr-2002 } 07 \text { UTC }
\end{aligned}
$$

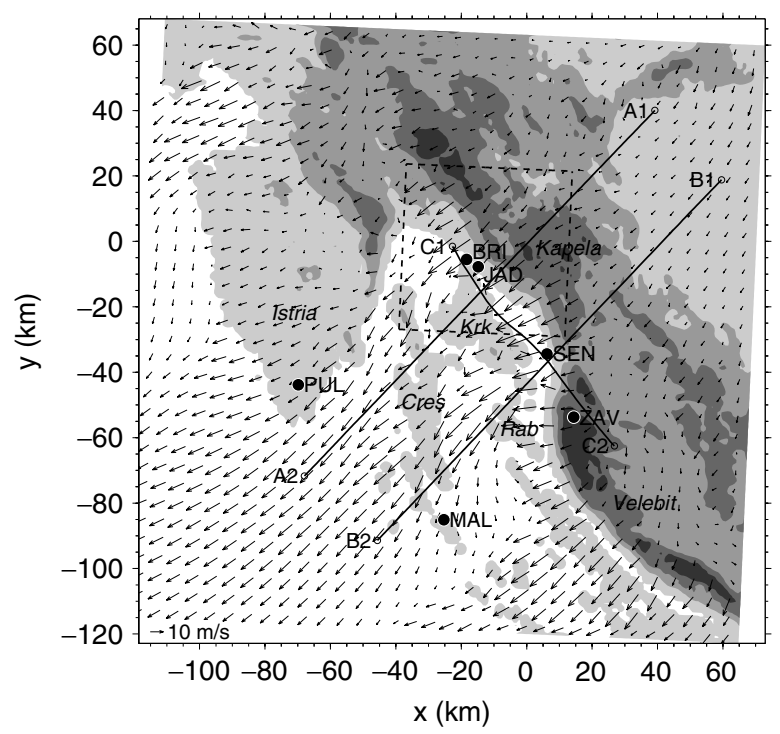

(b)

RAMS bora110, Wind Speed $(\mathrm{m} / \mathrm{s})$, z=300 m, 04-Apr-2002 07 UTC

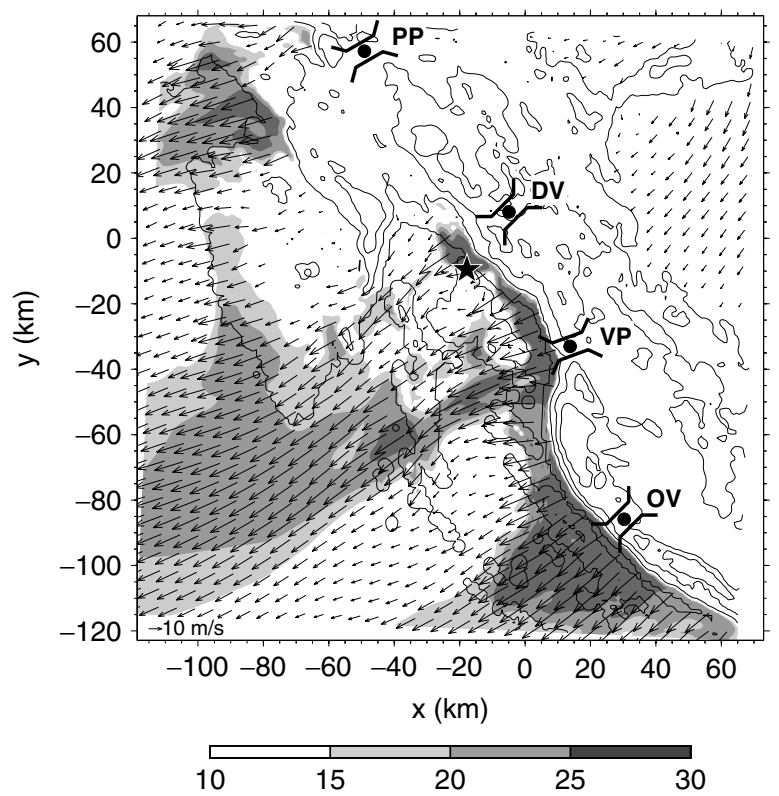

Figure 2. Topography of the northern part of the Dinaric Alps, as represented in the RAMS model domain 5, and simulated low-level winds of the RAMS reference run (grid 5) valid for 07 UTC on 4 April 2002. Horizontal wind vectors at (a) about $15 \mathrm{~m}$ AGL and (b) $300 \mathrm{~m}$ AMSL (see lower-left corner for reference vector). The grey-shaded elevation contours in (a) and the black elevation contour lines in (b) start at $0 \mathrm{~m}$ with increments of $400 \mathrm{~m}$. The grey-shaded contours for horizontal wind speed at $300 \mathrm{~m}$ AMSL in (b) start at $15 \mathrm{~ms}^{-1}$ with increments of $5 \mathrm{~ms}{ }^{-1}$. Three-letter labels in (a) mark the locations of weather stations, and solid lines (e.g. A1-A2) indicate cross-sections shown in the following figures. The dashed box in (a) encloses model domain 6. The following mountain gaps are indicated in (b): Postojna Pass ('PP') at $693 \mathrm{~m}$ AMSL; Delnička Vrata ('DV') at 742 m AMSL near Benkovac Fužinski ( 800 m); Vratnik Pass ('VP') at 698 m AMSL near Senj; and Oštarijska Vrata ('OV') at 928 m AMSL near Baške Oštarije. The star in (b) shows the location of Rijeka airport on Krk Island.

between the surface and the atmosphere are computed by the prognostic sub-model LEAF-2 (Walko et al., 2000), using similarity theory following Louis et al. (1982).

Most relevant to the present study is the turbulence parametrization, which partly differs from that of Gohm and Mayr (2005). In all domains, except for the highestresolution grid 6 , the model assumes complete decoupling of horizontal and vertical turbulent diffusion: vertical mixing is parametrized with a Mellor-Yamada 1.5-order, level-2.5 scheme (Mellor and Yamada, 1974, 1982), which is based on a prognostic equation for TKE and has been modified for the case of growing turbulence (Helfand and Labraga, 1988). Horizontal mixing is parametrized with a Smagorinsky-type first-order closure scheme (Smagorinsky, 1963). Hereafter we refer to this combination as the MY-SM scheme.

In the MY-SM scheme, the horizontal mixing coefficient for momentum is defined as:

$$
K_{\mathrm{mh}}=\rho_{0} \max \left\{K_{\min },\left(C_{\mathrm{x}} \Delta x\right)^{2} \sqrt{S^{2}}\right\}
$$

expressed in terms of the horizontal deformation

$$
S^{2}=2\left\{\left(\frac{\partial u}{\partial x}\right)^{2}+\left(\frac{\partial v}{\partial y}\right)^{2}\right\}+\left(\frac{\partial u}{\partial y}+\frac{\partial v}{\partial x}\right)^{2},
$$

the reference-state air density $\rho_{0}$, and a lower threshold value

$$
K_{\min }=0.075 K_{\mathrm{A}}(\Delta x)^{4 / 3}
$$

Here $C_{\mathrm{x}}$ and $K_{\mathrm{A}}$ are user-selectable dimensionless parameters, which have been set to $C_{\mathrm{x}}=0.2$ and $K_{\mathrm{A}}=1$ in the reference run. The horizontal mixing coefficient for scalars (heat and moisture) is $K_{\mathrm{hh}}=3 K_{\mathrm{mh}}$. Horizontal diffusion is computed according to true horizontal instead of terrain-following gradients. In model domain 6 , the reference simulation uses the Deardorff (1980) TKEbased closure for both the vertical and the horizontal mixing. This parametrization, herein referred to as the DD scheme, is suitable for very high model-grid resolutions with comparable horizontal and vertical mesh sizes $(\Delta x \approx \Delta z)$.

We performed several sensitivity simulations with different turbulence parametrizations (see Section 6). In principle, these simulations are based either on the MY-SM scheme in grids 1-6 with different settings for the SM part (i.e. different $C_{\mathrm{x}}$ and $K_{\mathrm{A}}$ ) or on the MY-SM scheme in grids 1-5 together with an isotropic SM scheme in grid 6 that applies SM for both vertical and horizontal mixing. In the latter case, herein referred to as 'iso-SM', the horizontal and vertical diffusion coefficients are identical, i.e. $K_{\mathrm{mh}}=K_{\mathrm{mv}}$ for momentum and $K_{\mathrm{hh}}=K_{\mathrm{hv}}$ for scalars. In this case, Equation (1) contains corrections based on the Brunt-Väisälä frequency (Hill, 1974) and the Richardson number (Lilly, 1962), and Equation (2) is based on a three-dimensional analogue. Further, in Equation (1), $C_{\mathrm{x}} \Delta x$ is replaced with $C_{\mathrm{z}} \Delta z$, and no minimum value $K_{\min }$ is imposed on the mixing coefficient. Table I summarizes the settings of the 
Table I. Description of RAMS simulations: type of turbulence parametrization, with parameter settings for reference, and sensitivity simulations. See text in Section 2.1 for further explanation.

\begin{tabular}{llcl}
\hline Name & Model grid 1-5 & Model grid 6 & Figures \\
\hline reference run & MY-SM, $C_{\mathrm{x}}=0.200, K_{\mathrm{A}}=1.0$ & DD & $2 ; 5-13 ; 16$ \\
MYSM-135-10 & MY-SM, $C_{\mathrm{x}}=0.135, K_{\mathrm{A}}=1.0$ & as in grids $1-5$ & $15(\mathrm{a}, \mathrm{d}) ; 16$ \\
MYSM-320-01 & MY-SM, $C_{\mathrm{x}}=0.320, K_{\mathrm{A}}=0.1$ & as in grids $1-5$ & $15(\mathrm{~b}, \mathrm{e}) ; 16$ \\
ISOSM-320-01 & MY-SM, $C_{\mathrm{x}}=0.320, K_{\mathrm{A}}=0.1$ & iso-SM, $C_{\mathrm{z}}=0.320$ & $15(\mathrm{c}, \mathrm{f}) ; 16$ \\
\hline
\end{tabular}

turbulence parametrization for the simulations presented in the following sections.

\subsection{The shallow-water model}

The numerical single-layer simulations in this study are performed with the shallow-water model (SWM) developed by Schär and Smith (1993). Similar to our approach here, this model has been used for studying flow past realistic three-dimensional orography, and applied to gap winds downstream of an island (Pan and Smith, 1999) and of an Alpine mountain pass (Gohm and Mayr, 2004). Our model version is based on a dimensionless form of the hydrostatic shallow-water equations for a single layer with constant density. The effects of the Earth's rotation and surface friction are neglected. The neglect of Coriolis effects is justified to a first approximation since we are primarily interested in the flow field close to the Dinaric Alps with typical length scales of less than $50 \mathrm{~km}$, and therefore large Rossby numbers $R o>1$. For a more detailed description of the model, see Gohm and Mayr (2004), where a very similar set-up is used. The topography of the Dinaric Alps is resolved on a rectangular mesh with $537 \times 553$ grid points and with a horizontal grid spacing of $500 \mathrm{~m}$. Details on initial conditions are given in Section 4.3.2.

\subsection{Measurements}

The key instrument used in this study is the DLR aerosol back-scatter lidar ALEX (Mörl et al., 1981), which was operated on board the DLR Falcon 20E aircraft in a nadirpointing mode at a constant altitude of about $6.1 \mathrm{~km}$ AMSL. The resolution of the lidar dataset is $15 \mathrm{~m}$ in the vertical direction and about $90 \mathrm{~m}$ in the horizontal. We will show back-scatter intensities from the $532 \mathrm{~nm}$ and $1064 \mathrm{~nm}$ wavelength channels. The back-scattered light gives a measure of the aerosol and cloud-particle load in the atmosphere. See Gohm and Mayr (2005) for a more detailed description of the lidar data. In addition to the aircraft, we used an instrumented car (Mayr et al., 2002) for mobile measurements on the leeward side of the Dinaric Alps, as well as a radio-sounding system, together with an automatic weather station at Jadranovo, on the coast. These project-specific measurements complement routine observations from several SYNOP stations, the upstream radio-sounding site at Zagreb, and the wind station on Krk Bridge. Measurement sites are indicated in Figures 1(c) and 2(a).

\section{Overview of the event}

3.1. Synoptic and meso- $\alpha$-scale analysis

The bora of 4 April 2002 is associated with a cyclogenesis over the western Mediterranean. In the afternoon of 3 April, a cut-off process in the upper troposphere reactivates a weak surface depression near the eastern coast of the Iberian peninsula. By the morning of 4 April, the fully-developed cyclone has moved towards the coast of Sardinia. Figure 1(a,b) shows the synoptic situation at 06 UTC on 4 April 2002, based on the ECMWF analysis. The depression over the Mediterranean, which has become established throughout the troposphere, is responsible for a low-level and southwestward-directed synoptic pressure gradient in the Adriatic region. A highpressure system over Scandinavia advects cool Arctic air towards central and southeastern Europe. The meso- $\alpha$ scale situation at the surface in the vicinity of the target area is described by the Vienna Enhanced-Resolution Analysis (VERA) (e.g. Steinacker et al., 2000) as shown in Figure 1 $(\mathrm{c}, \mathrm{d})$. Cold-air advection towards the Dinaric Alps is associated with northeasterly low-level winds and a horizontal gradient of potential temperature that is essentially parallel to the surface flow.

These two ingredients - the advection of cold air from the upstream side and the low-level synoptic pressure gradient across the Dinaric Alps - are responsible for the initiation of the northeasterly bora flow on the western (downstream) side of the coastal mountain range. Descending airflow, associated with atmospheric gravity waves (see Section 4.3), causes a mesoscale pressure gradient across the coastal ridge, which appears as densely-packed isobars in Figure 1(c). The event is classified as a cyclonic and shallow bora, because of the influence of the Mediterranean cyclone (e.g. Defant, 1951) and the restriction of the cross-mountain flow to a relatively shallow tropospheric layer, respectively. This latter feature has also been used to distinguish shallow from deep Alpine föhn (Gohm and Mayr, 2004). In this bora case, the cross-mountain flow is restricted to a layer below about $3 \mathrm{~km}$ AMSL. Above the bora layer and over the northern part of the Dinaric Alps, the wind direction changes with height, from nearly ridge-parallel geostrophic winds at $700 \mathrm{hPa}$ (Figure 1(b)) to weakly reversed (southwesterly) winds at $300 \mathrm{hPa}$ (Figure 1(a)). Such a vertical flow structure, with winds turning with height, indicates the existence of a critical level, which significantly dampens vertically-propagating gravity waves that are excited by the orography (e.g. Shutts, 
1995). Therefore, this case is significantly different from the event of 28 March 2002 investigated by Gohm and Mayr (2005), which was a deep anticyclonic bora and had no critical level. The shallow cyclonic bora appears to be the more frequent case, at least according to the dataset of the ALPEX experiment (Smith, 1987).

The bora event ends in the evening of 4 April, at a time when the centre of the eastward-moving cyclone has reached the Italian peninsula (not shown) and the depression has weakened. Consequently, the cross-barrier synoptic pressure gradient, which is one of the driving forces of the bora flow, weakens. In terms of reducedgravity shallow-water theory, this development can be seen as a reduction of the difference between the reservoir heights upstream and downstream of the mountain. Such a reservoir-height difference in the vicinity of the mountain, however, is a key feature of asymmetric flows over barriers. In such an asymmetric flow regime, the layer height of the partially-blocked flow upstream of the obstacle is greater than the height of the downstream reservoir to which the lee-side supercritical shooting flow adjusts via a hydraulic jump (e.g. Gohm and Mayr, 2004). This issue is discussed in further detail in Section 4.3.2.

\subsection{The meso- $\beta$-scale flow structure}

The meso- $\beta$-scale pattern of the bora flow is depicted in Figure 2, which shows the northern part of the Dinaric Alps - the main target area of our study - with the Kapela and Velebit mountain ranges. The peninsula of Istria forms the Kvarner Bay, which comprises several islands, such as Krk, Cres and Rab. The coastal mountain range has several embedded mountain passes, or gaps, which are favoured locations for northeasterly flows to pass the coastal range. The deepest and most prominent pass, with respect to bora frequency and severity, is the Vratnik Pass upstream of the town of Senj, which has been the subject of many bora studies (e.g. Bajić, 1991; Belušić et al., 2004; Gohm and Mayr, 2005). In the following sections, we will focus on a less deep and less well-studied gap called Delnička Vrata (The name means 'Doors of Delnice' (D. Belušić, personal communication). The actual pass is about $100-150 \mathrm{~m}$ higher than the landmark Delnička Vrata, and located about $15 \mathrm{~km}$ southwest of the town of Delnice, but has to our knowledge no distinct name.) (742 m AMSL, 'DV' in Figure 2(b)), with a width of about $20 \mathrm{~km}$. This gap is located immediately upstream of the northern tail of Krk Island, where the airport of Rijeka is situated and where a $1.4 \mathrm{~km}$-long and $60 \mathrm{~m}$-high bridge connects the island to the mainland. Therefore, the airport and the bridge are frequently exposed to strong and sometimes hazardous gap jets: a circumstance that affects air- and road-traffic safety in this area.

Figure 2 shows the wind field of the RAMS reference run of model domain 5 at 07 UTC on 4 April 2002. The near-surface winds at about $15 \mathrm{~m}$ AGL are shown in Figure 2(a), and the winds at $300 \mathrm{~m}$ AMSL in Figure 2(b). Strong bora winds are found in a narrow band along the coastline. Further downwind, they occur as well-defined jets emanating from four mountain gaps. Jet wind speeds are typically greater than $15 \mathrm{~ms}^{-1}$ near the surface and greater than $25 \mathrm{~ms}^{-1}$ at $300 \mathrm{~m}$ AMSL. Similar to the wind pattern discussed by Gohm and Mayr (2005), a relatively broad jet forms downstream of Cres Island as a result of the merging of two individual jets, one originating at Vratnik Pass and the other at Delnička Vrata. The southern boundary of this broad jet represents a distinct shear line, and is associated with a potentialvorticity (PV) anomaly, or 'PV banner' (e.g. Grubišić, 2004; Gohm and Mayr, 2005). Also noticed in previous studies, and obvious in Figure 2, is a wake region, with weak winds, immediately to the south of this shear line. The wake is bounded to the south by another gap jet, which originates at Oštarijska Vrata, a pass embedded in the Velebit range ('OV' in Figure 2(b)). It is noteworthy that this second low-level gap jet was not observed in the case of a weak and deep bora discussed in Gohm and Mayr (2005), where separation of the bora flow from the steep slopes of the high Velebit range caused weak surface winds of less than $10 \mathrm{~ms}^{-1}$ to the lee of the Velebit and consequently allowed the above-described wake region to extend much further southeastward. In this respect, the flow pattern of the present case is more similar to the event discussed by Grubišić (2004) and Jiang and Doyle (2005).

Although in the meso- $\beta$ scale, as depicted in Figure 2, the bora flow at 07 UTC appears to be fully developed, we will see in Section 5 that on the smaller meso- $\gamma$ scale close to the coast the bora flow has not yet become fully established everywhere. During the morning hours of 4 April, and specifically in the vicinity of Krk Island, the flow shows strong transient behaviour.

\subsection{Temporal evolution at the surface}

\subsubsection{Wind at Krk Bridge}

The temporal evolution of the bora flow near the coast in the northern Adriatic is illustrated in Figure 3 with wind observations from a weather station situated on Krk Bridge. The location of this station is indicated in Figure 2(a) ('BRI'). In order to highlight periods of bora flow, we have chosen a subjective criterion based on wind gusts exceeding a threshold value of $10 \mathrm{~ms}^{-1}$ for a period greater than $15 \mathrm{~min}$. This simple criterion is not physically based, like that of Vergeiner (2004), and so would not be appropriate as a general criterion applicable to any bora case. Nevertheless, in our case the criterion identifies three episodes of strong northeasterly winds, i.e. flow across the coastal ridge, which is a major characteristic of bora. Temperature and humidity measurements, which would highlight the change of air mass at the time of the bora breakthrough, are unavailable at this site.

The three bora episodes indicated in Figure 3 are separated by two short periods (of a few hours) with weakwind conditions. The onset of the first bora episode occurs in the afternoon of 3 April at about 15 UTC. Gusts 


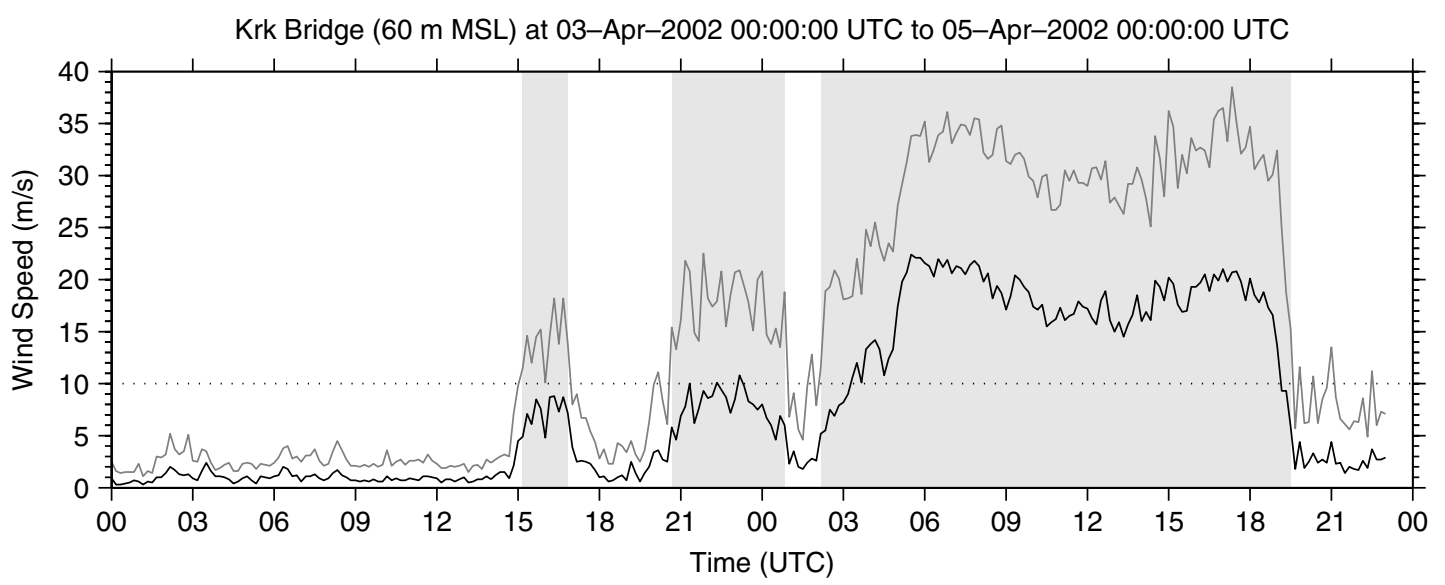

Figure 3. Time series of (solid line) sustained wind speed and (grey line) wind gusts, observed at the weather station at Krk Bridge at $60 \mathrm{~m}$ AMSL over $48 \mathrm{~h}$ beginning at 00 UTC on 3 April 2002. Periods with bora flow are indicated by shaded areas, and are derived according to a subjective criterion: gusts exceeding $10 \mathrm{~ms}^{-1}$ for at least $15 \mathrm{~min}$.

do not exceed $20 \mathrm{~ms}^{-1}$, and sustained winds are generally below $10 \mathrm{~ms}^{-1}$. The main breakthrough at Krk Bridge occurs in the early morning of 4 April at approximately 02 UTC. This bora period lasts until about 19:30 UTC, and has wind gusts exceeding $35 \mathrm{~ms}^{-1}$ and sustained wind speeds of more than $20 \mathrm{~ms}^{-1}$. It is likely that the bora front, which is a narrow zone to the lee of the coastal ridge where the bora separates from the surface through a hydraulic-jump-like behaviour, was located close to the coast during the night of 3-4 April. However, the front was not stationary, but was moving slightly back and forth, causing intermediate near-calm conditions. To summarize, the initial stage of this event has a complicated transient structure with unsteady winds. We will see in Section 5 that the exact time of the bora onset at the coast, and thus the bora duration, depends strongly on the location, and may vary by several hours even within a short distance (of a few kilometres) along the coast.

\subsubsection{Car transect}

Figure 4 highlights the main breakthrough phase of the bora on the morning of 4 April 2002. It shows near-surface measurements taken with the instrumented car, which drove along a northeast-southwest transect downstream of Delnička Vrata. The car starts at about $850 \mathrm{~m}$ AMSL, follows the lee slope of the coastal mountains down to Krk Bridge, and crosses the northern part of Krk Island, continuing to the west coast of the island (see Figure $4(\mathrm{~d}, \mathrm{e})$ ). This transect has been driven three times between 05:34 UTC and 09:29 UTC, along two identical legs and a third one that is only slightly different at the lee slope. Krk Bridge is indicated in Figure $4(\mathrm{a}-\mathrm{d})$ at $x=0$. One of the salient features in the evolution of the surface potential temperature and water-vapour mixing ratio (see Figure $4(a, b)$ ) is the warming and drying that occurs over Krk Island $(x>0)$ between the earliest and the intermediate leg. The potential-temperature increase of up to $5 \mathrm{~K}$ and the humidity decrease of up to $1.5 \mathrm{~g} \mathrm{~kg}^{-1}$ are strongest at two shallow sinks of the island's topography, as well as at the island's southwest coast. We believe that this drastic change of potential temperature and humidity between about 06 and 08 UTC is the result of an air-mass exchange due to strengthening northeasterly winds during the morning hours, which remove the two shallow cold pools. The bora front, however, has not yet propagated across the island. In the early transect, the peak of potential temperature southwest of Krk Bridge at $x=$ $5 \mathrm{~km}$ indicates the location of the bora front. This means that between the main breakthrough observed at Krk Bridge at 02 UTC (Figure 3) and the car measurements around 06 UTC, the front has moved downstream by not more than $5 \mathrm{~km}$. In the later two transects, the jump is located within the region $5 \mathrm{~km} \lesssim x \lesssim 10 \mathrm{~km}$, which is characterized by an increase of potential temperature in a downstream direction. In the RAMS reference run, which depicts the situation qualitatively well, the jump propagates between 06 and 09 UTC from $x=2 \mathrm{~km}$ to $x=5 \mathrm{~km}$ (not shown).

In the early and intermediate legs, we observe a continuous increase in potential temperature of 3-5 K as we move downstream along the lee slope. This feature is probably a result of turbulent mixing in the bora layer, which causes a downward heat flux: potentially-cool near-surface air spills over the pass and becomes mixed with potentially-warmer air from aloft, resulting in a downstream increase of near-surface potential temperature. Warming that occurs over the lee slope $(x<0)$ between the intermediate and late legs is related to daytime heating and the removal of the stable nocturnal boundary layer (see Figure 4(a)). Since this process occurs also on the upstream side of the mountain, the warming on the lee slope is presumably a combination of two effects: advection of warmer air from the upwind side, and local solar heating. The fullyevolved bora case hardly shows spatial variations in the surface potential temperatures downstream of the ridge, except from typical daytime fluctuations and a slight increase of about $2 \mathrm{~K}$ between the pass and the island. This spatial pattern is supported by at least three more 
(a)
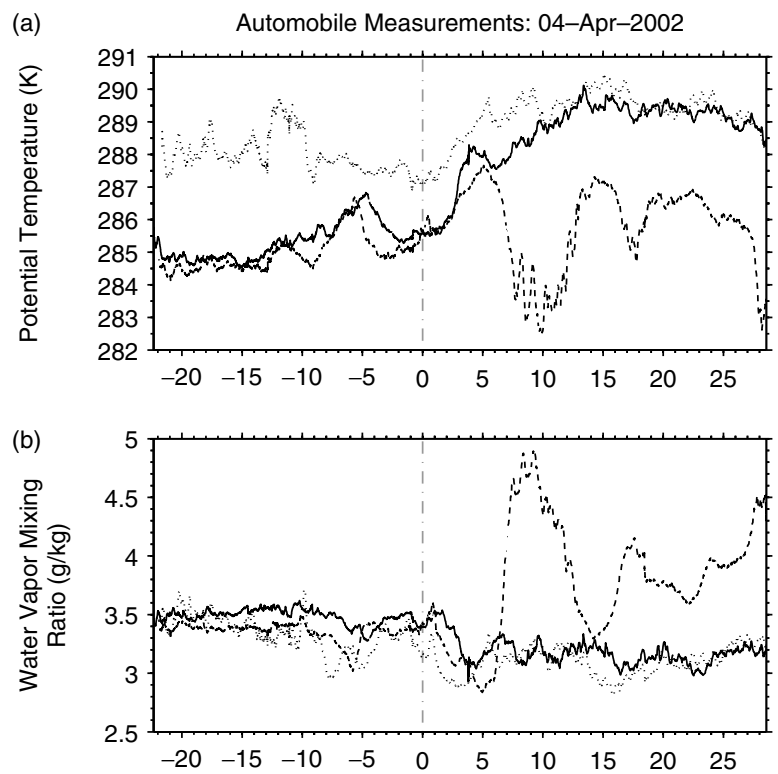

(c)

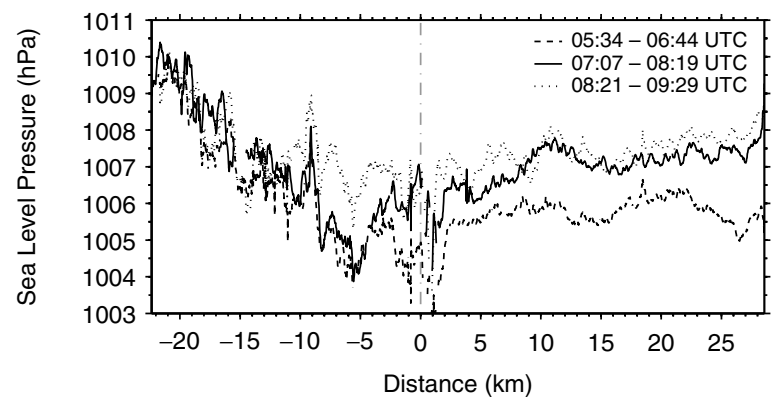

(d)

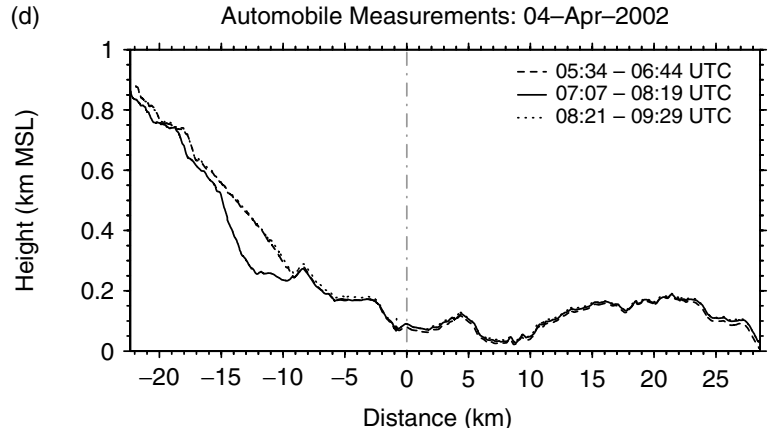

(e)

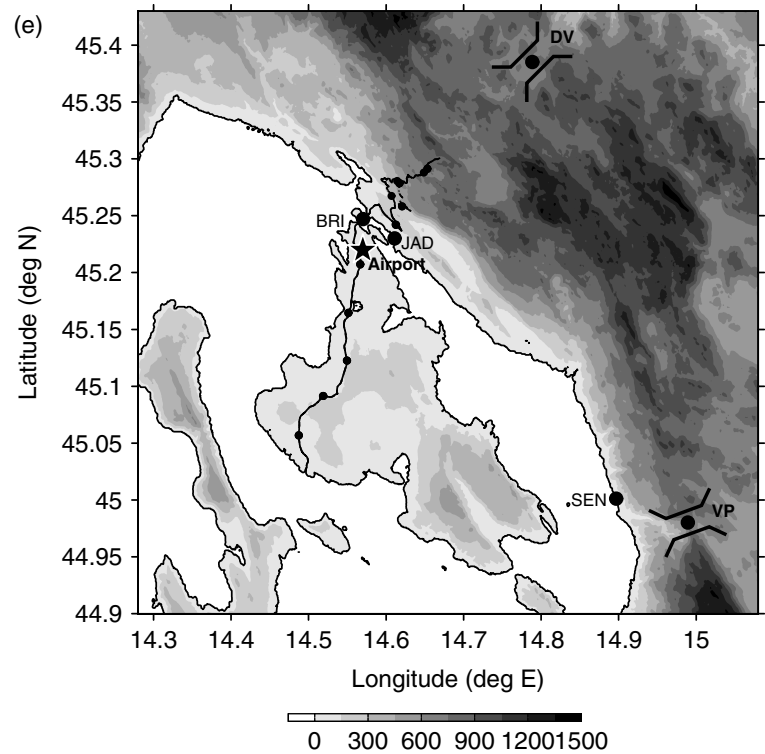

Figure 4. Near-surface observations collected on 4 April 2002 with the instrumented car on the leeward side of the Dinaric Alps: (a) potential temperature; (b) water-vapour mixing ratio; (c) mean sea-level pressure; (d) GPS height of the car AMSL; (e) car track. Data are shown for three different periods for nearly the same transect: (dashed line) 05:34-06:44 UTC; (solid line) 07:07-08:19 UTC; (dotted line) 08:21-09:29 UTC. In (e), grey-shaded elevation contours start at $0 \mathrm{~m}$ AMSL with $150 \mathrm{~m}$ increments. The transect is aligned from northeast to southwest, along the lee slope of the coastal mountain range and across Krk Island. The location of Krk Bridge is indicated by the grey dash-dotted line in (a)-(d), and by the label 'BRI' in (e). Other sites shown in (e) are Jadranovo ('JAD') and Senj ('SEN'); passes and the airport are marked as in Figure 2(b). Markers every $5 \mathrm{~km}$ along the car track in (e) correspond to major ticks on the $x$ axis of (a)-(d).

legs, which were repeated until 13 UTC (not shown). Therefore, a bora with a neutral (daytime) boundary layer upstream of the mountain shows less spatial variation in surface potential temperature on the downstream side than a bora with a stably-stratified (night-time) boundary layer. In the latter case, turbulence causes a significant warming along the lee slope due to downward mixing of potentially-warmer air.

The mean sea-level pressure shown in Figure 4(c) was derived from the car's surface-pressure, temperature and height measurements by assuming a constant lapse rate of $6.5 \mathrm{~K} \mathrm{~km}^{-1}$. The error in sea-level pressure introduced by assuming a constant lapse rate instead of a 'true' temperature profile is estimated to be less than $1 \mathrm{hPa}$. The height data were collected with the car's Global Positioning System (GPS) sensor, which recorded an estimated error for the vertical position measurements of 10-20 m. Therefore, features in Figure 4(c) with magnitudes less than about $1 \mathrm{hPa}$ lie below the instrument's precision limit and are not significant. Despite the limited quality of the derived reduced pressure, a clear decrease of sea-level pressure is observed in all three legs along the lee slope, with a local minimum near the coast. From there on, the pressure increases slightly in the downstream direction for a few kilometres, before settling at a near-constant level. The total decrease of sea-level pressure from the pass to the coast is about $6 \mathrm{hPa}$, i.e. about twice as much as is captured by the mesoscale analysis in Figure 1(c). The corresponding local pressure minimum to the lee of the mountain is a result of gravity-wave breaking, which forms an elevated region of neutral buoyancy that induces a negative pressure perturbation at the surface (see Section 5.1 for supporting model results). The 'footprint' of the hydraulic jump can be identified by a fairly continuous pressure increase over $1 \mathrm{~km} \lesssim x \lesssim 10 \mathrm{~km}$.

\section{Comparison of simulations and observations}

\subsection{Vertical profiles}

Figures 5 and 6 illustrate the basic vertical flow structure upstream and downstream of the Dinaric Alps, as 

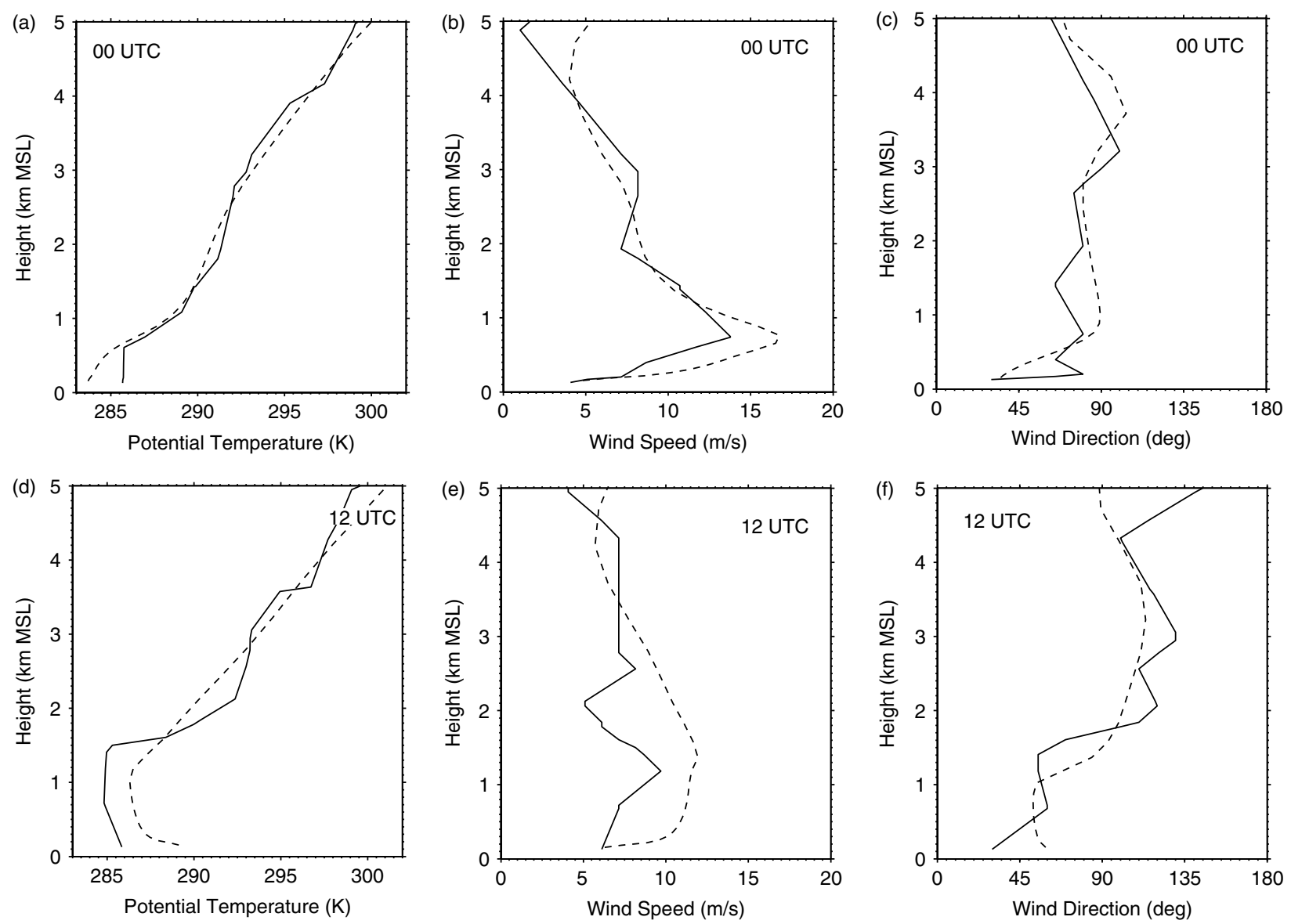

Figure 5. Comparison between observed (solid line) and simulated (dashed line, reference run, grid 4) vertical profiles at Zagreb at (a,b,c) 00 UTC and (d,e,f) 12 UTC on 4 April 2002: (a,d) potential temperature; (b,e) horizontal wind speed; (c,f) wind direction. See Figure 1(c) for location of Zagreb.
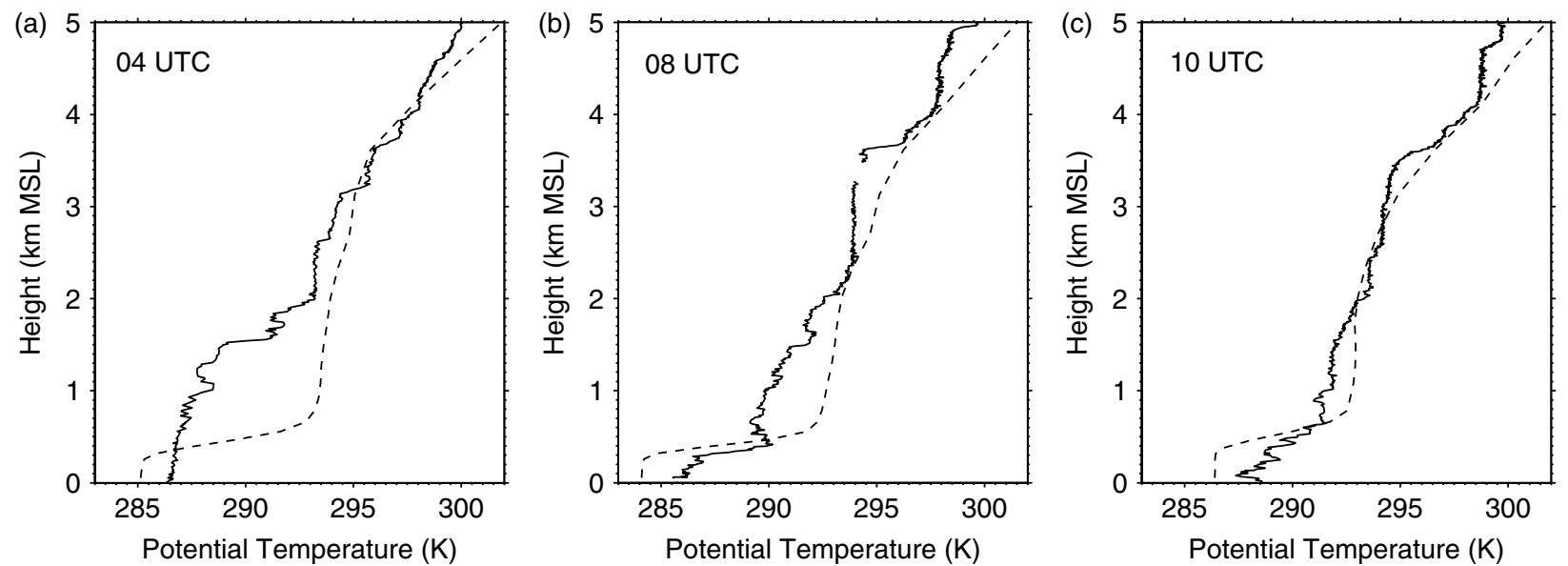

Figure 6. Comparison between observed (solid line) and simulated (dashed line, reference run, grid 6) vertical profiles of potential temperature at Jadranovo on 4 April 2002: (a) 04 UTC; (b) 08 UTC; (c) 10 UTC. See label 'JAD' in Figure 2(a) and Figure 4(e) for location of Jadranovo. Because of interference affecting the GPS signal, no wind information is available.

observed by radiosondes and as represented in the reference run. Model data are from grid 4 in Figure 5 and from grid 6 in Figure 6.

\subsubsection{Upstream profile}

The airflow upstream of the Dinaric Alps at Zagreb is shown in Figure 5. The soundings from 00 and
12 UTC describe the background flow of the early and mature stage of the bora respectively. This flow impinges on the coastal mountain range, and forms the bora on the leeward side. The location of Zagreb is indicated in Figure 1(c). The observed sounding at 00 UTC (Figure 5(a,b,c)) shows a stably-stratified atmosphere with a shallow neutral layer (about $400 \mathrm{~m}$ deep) 
near the surface. The wind profile indicates the existence of a strong low-level jet (LLJ) with peak winds of about $15 \mathrm{~ms}^{-1}$. Two possible physical mechanisms for the genesis of this night-time LLJ are inertial oscillation and flow-splitting around the Alps (see Gohm and Mayr (2005)). It is important to notice that winds in the lower troposphere are generally blowing from easterly (crossbarrier) directions.

The model captures the basic thermodynamic and flow structure. However, it does not reproduce the shallow neutral layer. The model has a cold bias of about $2 \mathrm{~K}$ near the surface, and slightly overestimates (by about $3 \mathrm{~ms}^{-1}$ ) the wind-speed maximum of the LLJ. A closer inspection of observations indicates that the observed potential temperature from the SYNOP station at Zagreb at $00 \mathrm{UTC}$ is about $1.5 \mathrm{~K}$ lower than the near-surface temperatures from the radio-sounding (see Figures 5(a) and 7(a)). Thus, the model's near-surface temperature agrees better with the SYNOP report. This would suggest that the observed sounding has, at least near the surface, a warm bias. Consequently, the shallow neutral layer depicted in the profile of Figure 5(a) should be rather stable.

By 12 UTC (Figure 5(d,e,f)), a neutrally-stratified convective mixed layer (CML) has evolved, extending up to a height of approximately $1.5 \mathrm{~km}$ AMSL. The CML is separated from the rest of the stably-stratified troposphere by a pronounced temperature inversion. The LLJ has basically disappeared. The simulated low-level flow is up to $40 \%$ stronger than the observed winds (Figure 5(e)). This over-prediction is less drastic (about 25\%) when compared with the ECMWF analysis (not shown). The CML is about $2 \mathrm{~K}$ too warm. Part of the warm bias at 12 UTC may be explained by the fact that the model underestimates the increasing cloud cover, which had been observed at Zagreb in the late morning, and therefore overestimates surface-layer heating. In contrast to the previous sounding, winds are turning with height from cross-barrier to along-barrier flow directions. This implies the existence of a critical level at about $2 \mathrm{~km}$ AMSL, which is in agreement with the analysis of Section 3.1. It is noteworthy that such a critical layer was not found in the deep-bora case discussed by Gohm and Mayr (2005); this implies that the deep- and shallow-bora cases differ with regard to gravity-wave dynamics.

In essence, the background flow, which impinges on the coastal barrier during the mature stage of the bora, has a two-layer structure in which the upper-tropospheric layer is dynamically decoupled from the CML by directional wind shear and by a temperature inversion. This two-layer structure is an important requirement for the application of reduced-gravity shallow-water theory, as performed in Section 4.3.2. In order to determine the hydraulic state of the impinging flow, we compute local Froude numbers for Zagreb based on the observed profiles shown in Figure 5. The computation is done similarly to that in Gohm and Mayr (2004). Let $H$ be the depth of the impinging bora flow, defined by the layer between the height $h$ of the surface and the centre height
$Z$ of the inversion. For cases in which the low-level flow is blocked by the mountain, $h$ would represent the top height of the stagnant layer. The depth of the inversion layer is $\Delta Z$. Let $U$ be the mean wind speed averaged over $H, \Delta \theta$ the difference in potential temperature across the stable layer $\Delta Z$ on top of the bora flow, and $\bar{\theta}$ the average potential temperature within the bora flow. From these parameters, which can be estimated from Figure 5, we can derive the reduced gravitational acceleration $g^{*}=g \Delta \theta / \bar{\theta}$, the local gravity-wave speed $c=\sqrt{g^{*} H}$, and the local Froude number $F=U / \sqrt{g^{*} H}$ (see Table II). For the 00 UTC profile, the 'inversion' is a deep stable layer rather than a well-defined inversion. The 12 UTC sounding, however, exhibits a shallow, sharp inversion, and is therefore better suited for the application of single-layer shallow-water theory. With typical local Froude numbers at Zagreb of 0.3-0.4, the bora flow upstream of the coastal barrier, approximately $2 \mathrm{~km}$ deep, is subcritical $(F<1)$.

Consider a two-layer flow in a channel with a rectangular cross-section in which the channel width gradually decreases and the bottom height increases. Such a configuration is similar to the actual situation upstream of a mountain gap. According to Arakawa (1969) (see also Pan and Smith (1999)), such a channel flow with an initially subcritical Froude number $F_{\infty}<1$ will become critical $(F=1)$ if the dimensionless ridge height $M=$ $\left(h_{\mathrm{m}}-h_{\infty}\right) / H_{\infty}$ exceeds the critical value:

$$
M_{\mathrm{c}}=1+\frac{1}{2} F_{\infty}^{2}-\frac{3}{2}\left(\frac{F_{\infty}}{D_{\mathrm{c}}}\right)^{2 / 3} .
$$

Here $h_{\infty}$ and $F_{\infty}$ are the terrain height and Froude number respectively, far upstream of the mountain; $h_{\mathrm{m}}$ is the absolute crest height; $h_{\mathrm{m}}-h_{\infty}$ is the crest height relative to $h_{\infty} ; H_{\infty}$ is the far-upstream depth of the lower fluid layer; and $D_{\mathrm{c}}$ is the ratio of the channel width at the critical point to its upstream value. Note that in Arakawa (1969) the upstream terrain height is $h_{\infty}=$ 0 , so that the dimensionless mountain height reduces to $M=h_{\mathrm{m}} / H_{\infty}$. For a straight channel, i.e. $D_{\mathrm{c}}=1$, Equation (4) reduces to the simpler form for a onedimensional flow over an infinitely long ridge (Long, 1954). Using data for the Zagreb profile at 12 UTC from Table II for the far-upstream condition, we derive $M_{\mathrm{c}}=0.37$, based on $F_{\infty}=0.3$ and $D_{\mathrm{c}}=1$. This value corresponds to a critical mountain height $h_{\mathrm{m}}=M_{\mathrm{c}} H_{\infty}+$ $h_{\infty} \approx 900 \mathrm{~m}$ AMSL. This is the minimum mountain height necessary for the occurrence of critical flow at the crest, and therefore for flow transition from subcritical to supercritical $(F>1)$ as the fluid passes the mountain. In such a situation, the layer height would continuously descend and the flow would accelerate. Typical values for the crest height in our target area range from $1000 \mathrm{~m}$ to $1500 \mathrm{~m} \mathrm{AMSL}$, and are therefore larger than the critical mountain height, indicating flow transition. For a narrowing channel, i.e. $D_{\mathrm{c}}<1$, the critical mountain height $M_{\mathrm{c}}$ is smaller than for a straight channel. Thus, for a mountain gap, flow transition occurs at a lower gap 
Table II. Hydraulic parameters calculated from two radio-soundings: radiosonde ascents at Zagreb at 00 and 12 UTC on 4 April 2002. See text in Section 4.1.1 for further explanation.

\begin{tabular}{lcccccccccc}
\hline Time & $\begin{array}{c}h \\
(\mathrm{~m} \mathrm{AMSL})\end{array}$ & $\begin{array}{c}Z \\
(\mathrm{~m} \mathrm{AMSL})\end{array}$ & $\begin{array}{c}\Delta Z \\
(\mathrm{~m})\end{array}$ & $\begin{array}{c}H \\
(\mathrm{~m})\end{array}$ & $\begin{array}{c}U \\
\left(\mathrm{~ms}^{-1}\right)\end{array}$ & $\begin{array}{c}\Delta \theta \\
(\mathrm{K})\end{array}$ & $\begin{array}{c}\bar{\theta} \\
(\mathrm{K})\end{array}$ & $\begin{array}{c}g^{*} \\
\left(\mathrm{~ms}^{-2}\right)\end{array}$ & $\begin{array}{c}c \\
\left(\mathrm{~ms}^{-1}\right)\end{array}$ \\
\hline 00 UTC & 130 & 1910 & 2600 & 1780 & 9 & 7.4 & 286 & 0.25 & 21 & 0.4 \\
12 UTC & 130 & 2220 & 1450 & 2090 & 8 & 7.9 & 285 & 0.27 & 24 & 0.3 \\
\hline
\end{tabular}

height, compared to the height of an elongated ridge. The lower $M_{\mathrm{c}}$ is a result of confluence upstream of the gap. In our specific case, a $19 \%$ decrease of the channel width inside the gap (corresponding to $D_{\mathrm{c}}=$ 0.81 ) would be sufficient to cause flow transition at the Vratnik Pass, at $698 \mathrm{~m}$ AMSL the deepest gap in our target area. For the Delnička Vrata, at $742 \mathrm{~m}$ AMSL, a contraction of $16 \%\left(D_{\mathrm{c}}=0.84\right)$ would be sufficient. The complexity of the real topography of these two gaps, characterized by several embedded smaller-scale gaps, makes it difficult to approximate the larger-scale gap by a rectangular channel. Therefore, we do not estimate realistic values for $D_{\mathrm{c}}$, but refer to the numerical simulations of Section 4.3.2, which support the idea of flow transition at both gaps.

\section{4.l.2. Downstream profile}

Figure 6 depicts the thermodynamic structure of the bora flow downstream of the coastal mountains at three different times. The soundings were conducted at Jadranovo, a small town located on the coast about $4 \mathrm{~km}$ southeast of Krk Bridge (see Figure 4(e)), where a mobile radiosounding system had been set up specially for this case study. Profiles of potential temperature are shown for 04, 08 and 10 UTC. Wind observations are not shown, because of the poor quality of the radiosonde GPS signal, due to strong interference with an unknown noise source. The observed profiles nicely document the breakthrough of the bora. At 04 UTC a nearly-mixed layer extends to about $1 \mathrm{~km}$ AMSL, where it is topped by a temperature inversion. The inversion marks the upper boundary of the bora flow. By 08 UTC, the inversion has descended by about $1000 \mathrm{~m}$. The vertical structure at 10 UTC remains essentially the same. The 04 UTC sounding represents the profile just before the time of the bora breakthrough, while the other two soundings show the structure of the fully-developed bora. Data from a weather station located at Jadranovo (see Figure 8(b)) indicate that at 04 UTC sustained winds are generally weak (below $3 \mathrm{~ms}^{-1}$ ); however, individual gusts already exceed $10 \mathrm{~ms}^{-1}$. At the same time, winds at Krk Bridge are significantly stronger (see Figures 3 and 8(a)). This indicates that the bora front was located close to, but still upstream of, Jadranovo. The bora breakthrough occurred at Jadranovo around 06 UTC, i.e. about $4 \mathrm{~h}$ after the breakthrough at Krk Bridge. The different inversion heights before and after the bora front passage, i.e. between the 04 and 08 UTC soundings, can be explained by the concept of a propagating hydraulic jump. Upstream of the jump, i.e. in the supercritical part of the flow, the inversion is located at a lower altitude than downstream, in the subcritical part of the flow. Consequently, with the passage of the jump the altitude of the inversion decreases rapidly. This passage occurs around 06 UTC. Since Krk Bridge is located closer to the centre of the mountain gap than Jadranovo (see Figure 2), the gap jet first becomes established at Krk Bridge; this explains the earlier time of the breakthrough (see also Section 5).

Comparison of observations and simulation in Figure 6 reveals the largest discrepancy at 04 UTC and the best agreement at 10 UTC. Obviously, the model has a time lag, with a too-early breakthrough of the bora. This can be seen from the too-low temperature inversion in Figure 6. Furthermore, especially in the morning, the model overestimates the strength of the inversion. This leads to a cool bias below the inversion of about 1.5-2 K, and consequently a warm bias above the inversion. Above about $2 \mathrm{~km}$ AMSL, the agreement is good.

The overestimated inversion is rather unusual. Mesoscale models have rather a tendency to underestimate inversion strengths, due to coarse vertical resolution or strong smoothing by numerical diffusion. The overestimation found here may be a sign that turbulent mixing predicted by the large-eddy simulation (LES) scheme in the innermost model domain of the reference run is not strong enough. Less-sharp inversions at the top of the bora flow have been found in sensitivity simulations with different turbulence parametrization schemes (see Section 6).

\subsection{Surface characteristics}

In this section we will evaluate the ability of the model to simulate near-surface potential temperature (Figure 7) and wind speed (Figure 8). The reference run is compared with observations from several weather stations (see Figures 1(c), 2(a) and 4(e) for locations of stations). Not all stations have continuous data. Data gaps, i.e. missing SYNOP reports, occur especially during the night. Model data are taken from the highest-resolution grid available for each individual station (see figure captions).

The model captures the night-time cooling at Zagreb and Senj, but overestimates the daytime heating. This warm bias, as mentioned above, is caused by an underestimated cloud cover associated with the approaching cyclone. The bora breakthrough at Jadranovo is shown in Figures 7(b) and 8(b). The whole process lasts several hours. It starts at approximately 20 UTC on 3 April with a sudden increase of $4 \mathrm{~K}$ in potential temperature and an 

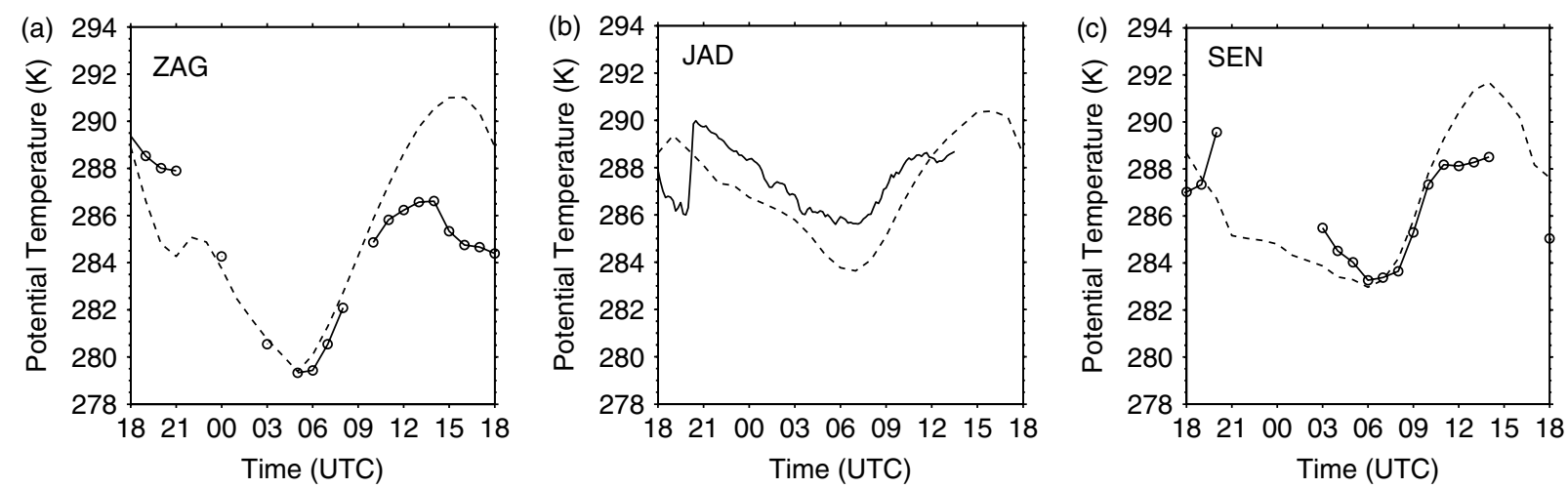

Figure 7. Comparison between observed (solid line) and simulated (dashed line, reference run) near-surface potential temperature, for a $24 \mathrm{~h}$ period starting at 18 UTC on 3 April 2002: (a) Zagreb ('ZAG') at $128 \mathrm{~m}$ AMSL; (b) Jadranovo ('JAD') at 2 m AMSL; (c) Senj ('SEN') at $28 \mathrm{~m}$ AMSL. Lines with circles in (a) and (c) represent hourly SYNOP observations (broken lines indicate missing data), while the straight solid line in (b) represents continuous data from an automatic weather station. Model data are taken from about $15 \mathrm{~m}$ AGL, and from grid 4 in (a), grid 6 in (b), and grid 5 in (c). The locations of the stations are shown in Figures 1(c), 2(a), and 4(e).
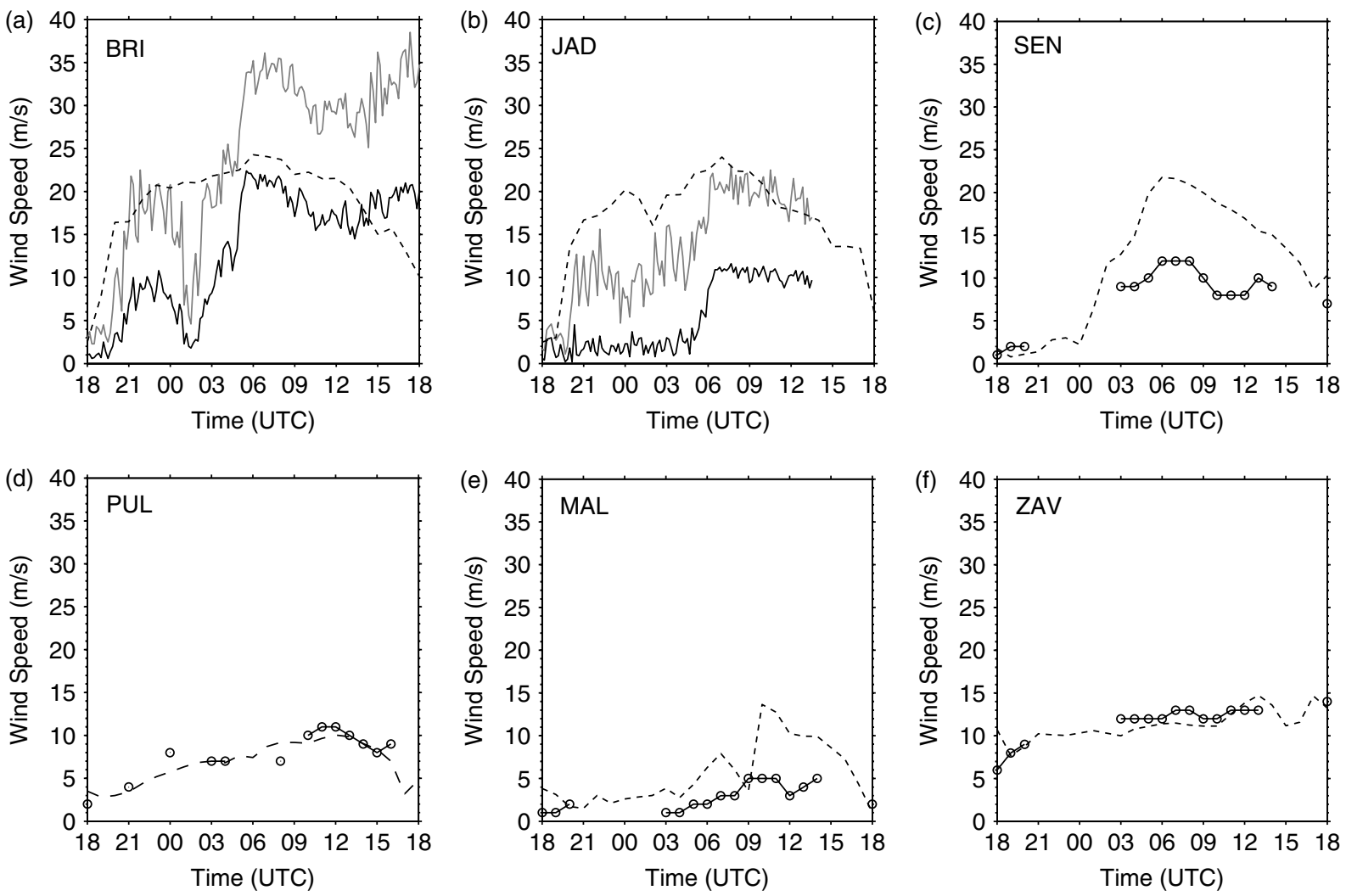

Figure 8. As Figure 7, but for near-surface wind speed. Data are from: (a) Krk Bridge ('BRI') at $60 \mathrm{~m}$ AMSL; (b) Jadranovo ('JAD') at $2 \mathrm{~m}$ AMSL; (c) Senj ('SEN') at $28 \mathrm{~m}$ AMSL; (d) Pula ('PUL') at $63 \mathrm{~m}$ AMSL; (e) Mali Lošinj ('MAL') at $53 \mathrm{~m}$ AMSL; (f) Zavižan ('ZAV') at $1597 \mathrm{~m}$ AMSL. Solid (grey) lines in (a) and (b) represent sustained wind speeds (wind gusts) from automatic weather stations, and lines with circles in (c)-(f) represent SYNOP observations. Model data are taken from about $47 \mathrm{~m}$ AGL for Krk Bridge, and from about $15 \mathrm{~m}$ AGL for the other stations. The grid-point data shown are from grid 6 in (a) and (b), and grid 5 in (c)-(f). The locations of the stations are shown in Figure 2(a).

increase in gust intensity up to $15 \mathrm{~ms}^{-1}$. Sustained wind speeds, however, remain weak (around $2 \mathrm{~ms}^{-1}$ ) until about 06 UTC on 4 April, when a sharp increase in sustained winds marks the actual breakthrough. We believe that this period of enhanced gusts but low mean winds indicates the existence of a hydraulic jump close to the site. The observed situation is similarly complex at Krk Bridge (see Figure 8(a) and discussion of Figure 3). The simulation shows a breakthrough already at 19 UTC on 3 April, and therefore does not capture this complex onset phase with relatively weak sustained winds but high gusts at Jadranovo and Krk Bridge (see Figure 8(a,b)). The cold model bias at Jadranovo revealed in Figure 7(b) agrees with the discussion of the vertical profile in Figure 6, and may be a sign that there is too little turbulent mixing in the model. 
Figure $8(a, b)$ reveals the failure of the model to predict the timing of the bora breakthrough near the coast. Nevertheless, the model captures the magnitude of the sustained wind speeds fairly well, not only at Krk Bridge but also further downstream at Pula and Mali Lošinj (Figure 8(d,e)), as well as at the mountain crest at Zavižan (Figure 8(f)). The discrepancy between observed and simulated wind speeds at Jadranovo may be partly related to the difference in the height of the anemometer and of the model grid point $(2 \mathrm{~m}$ versus $15 \mathrm{~m} \mathrm{AGL)}$ and the effect of local topography. The reason for the differences between modelled and observed wind speeds at Senj may be explained by the fact that the anemometer of the SYNOP station underestimates the true wind speed for northeasterly flow because of its sheltered position (Belušić and Klaić, 2004) (Depending on the wind speed, the bora flow may be underestimated by approximately $30 \%-40 \%$ (D. Belušić, personal communication). In summary, from Figure 8 we can state that the strongest sustained near-surface winds of $10-25 \mathrm{~ms}^{-1}$ occur downstream of mountain gaps, close to the coast (Krk Bridge, Senj, Jadranovo); are slightly weaker (below $15 \mathrm{~ms}^{-1}$ ) at the crest (Zavižan); and are significantly weaker (below $10 \mathrm{~ms}^{-1}$ ) several kilometres downstream of the main barrier (Pula and Mali Lošinj). This weakening of the near-surface winds with offshore distance is a result of the complex wake-jet structure of the flow (see Figure 2 and Section 3.2).

\subsection{Vertical flow structure across the Dinaric Alps}

In this section we elucidate the observed and simulated vertical structure of the bora along two crosssections (Figure 9). These transects are aligned parallel to the background flow in a northeast-southwest direction (see Figure 2(a)). Transect A1-A2 crosses the Dinaric Alps approximately $10 \mathrm{~km}$ southeast of Delnička Vrata, i.e. near the edge of this mountain gap, while transect B1-B2 passes through the centre of the Vratnik Pass.

\subsubsection{Lidar and RAMS}

The aerosol back-scatter intensity at $532 \mathrm{~nm}$ measured with the airborne lidar is shown in Figure 9(a,b). This can be compared with the simulated flow field of the RAMS reference run (grid 5) illustrated in Figure 9(c,d). Back-scatter intensities highlight the existence of several aerosol layers. Aerosols advected with the airflow behave as tracers. Consequently, aerosol layers do not stay at a constant altitude, but become deformed as the flow passes the mountain. The bottom and top boundaries of individual aerosol layers are well correlated with the alignment and behaviour of individual isentropes. The descent of observed aerosol layers, and simulated isentropes, on the leeward side of the coastal range is clear evidence for a descending and accelerating bora flow. As these aerosol layers are advected across the mountain, their structure becomes significantly less well defined. This leads to a more homogeneous aerosol distribution downstream of the mountain. The simulation suggests that this feature is a result of turbulent mixing occurring in the wave-breaking region as well as in the shear layer on top of the bora downstream of the crest. The wave patterns found in the fields of observed backscatter intensity and simulated potential temperature, with typical wavelengths of $10-20 \mathrm{~km}$, point to the existence of gravity waves that have been excited by individual mountains embedded in the overall ridge. Upstream of the coastal ridge, two layers with high back-scatter intensities are detectable. The lower one, between $1 \mathrm{~km}$ and $1.6 \mathrm{~km}$ AMSL, marks the top of the CML captured by the simulation, and also documented in Figure 5(d). A similar CML structure was described in Gohm and Mayr (2005) for a deep-bora case. The upper layer, at around $3 \mathrm{~km}$ AMSL, corresponds to a shallow stratus deck marking the top of the bora flow. This cloud layer evaporates on the leeward side of the mountain, because of descending motions. White stripes in the intensity field indicate missing data due to attenuation of the laser beam by cloud droplets that are presumably generated by rising motions in gravity waves (at $x \approx 120 \mathrm{~km}$ in Figure 9(a) and at $x \approx 70 \mathrm{~km}$ in Figure 9(b)). At approximately $4 \mathrm{~km}$ AMSL, the aerosol layers and isentropes are nearly horizontal, indicating weak gravity-wave activity as a result of wave damping in the wind-shear layer.

The model has a tendency to underestimate the amplitude of the short-wavelength non-hydrostatic gravity waves. This becomes obvious when comparing, for example, the wave fields in Figures 9(b) and 9(d) at an elevation of about $2 \mathrm{~km}$ AMSL, above the mountain. The same behaviour was documented in Gohm and Mayr (2005). We now believe that the horizontal diffusion applied in the reference simulation (here the MY-SM scheme in grid 5 - see Table I) is too strong. This topic is discussed in more detail in Section 7.

Differences between the two transects $\mathrm{A} 1-\mathrm{A} 2$ and $\mathrm{B} 1-\mathrm{B} 2$ are most prominent to the lee of the mountain range. Downstream of the Vratnik Pass (B1-B2), the bora is fully evolved, and strong low-level winds exceeding $15 \mathrm{~ms}^{-1}$ extend over many kilometres (Figure 9(d)). At Delnička Vrata (A1-A2), however, flow separation occurs on the lee slope (Figure 9(c)). This forms a wake about $30 \mathrm{~km}$ wide, downstream of the coast, with weak low-level winds. These different flow structures are mainly a result of different terrain properties. The Vratnik Pass is the deeper of the two gaps, and so facilitates the passage of the flow past the barrier, whereas higher terrain in $\mathrm{A} 1-\mathrm{A} 2$ favours flow separation as a result of the adverse pressure gradient underneath trapped gravity waves (e.g Doyle and Durran, 2002). Because of the lower terrain height at Vratnik Pass, the depth of the bora layer above the lee slope (about $1.2 \mathrm{~km}$ ) is twice that at Delnička Vrata. Greater bora-layer depths downstream of passes, compared with the leeward sides of higher terrain, were also found by Jiang and Doyle (2005). The deeper gap also seems to favour a slightly earlier breakthrough of the bora. 

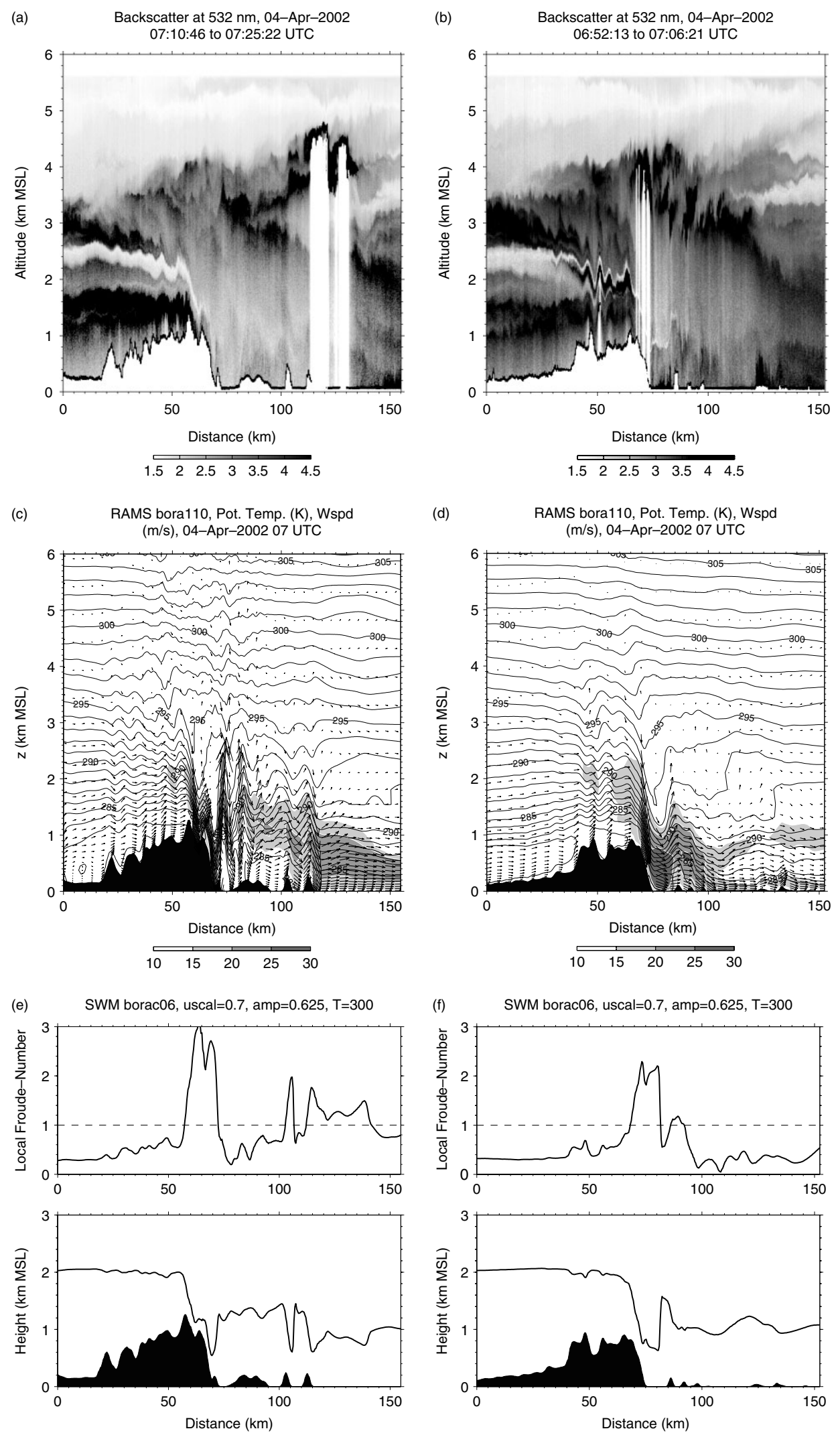

Figure 9. Vertical transects across the Dinaric Alps along the legs (a,c,e) A1-A2 and (b,d,f) B1-B2, from northeast to southwest as indicated in Figure 2(a). (a,b) Observed range-corrected back-scatter intensity (arbitrary units) at $532 \mathrm{~nm}$, on 4 April 2002: (a) 07:11-07:25 UTC; (b) 06:52-07:06 UTC. (c,d) RAMS reference run (grid 5) at 07 UTC on 4 April 2002: contour lines of potential temperature with $1 \mathrm{~K}$ increments; grey-shaded contours of horizontal wind speed with $5 \mathrm{~ms}^{-1}$ increments; wind vectors showing the components parallel to the cross-section. (e,f) SWM simulation at $\widehat{t}=300$ (see Section 4.3.2): local Froude number (top panels), and fluid-layer height (bottom panels). Orography is white in (a) and (b), and black in (c)-(f). 


\subsubsection{The SWM}

The two-layer structure of the background flow discussed in Section 4.1.1 suggests the application of an SWM. In this section we will investigate the ability of such a model to represent certain flow properties observed by the lidar and captured by the RAMS model. Twodimensional hydraulic theory has been used in many previous studies in order to describe the dynamics of bora (e.g. Klemp and Durran, 1987; Smith, 1987). These investigations, however, did not account for the three-dimensional structure of the topography. Our SWM accounts for a single fluid layer that is forced to flow over the realistic three-dimensional terrain of the Dinaric Alps. Thus, the influence of mountain gaps can be studied in a manner similar to that of Pan and Smith (1999) and Gohm and Mayr (2004). The SWM is initialized with a horizontally-homogeneous layer height, a constant flow speed, and a constant wind direction of 55. The model is integrated to a quasi-steady state, obtained after approximately 3000 integrations at a dimensionless time $\widehat{t}=t \sqrt{g^{*} H_{\infty}} / L=300$. Here, $H_{\infty}$ is the far-upstream fluid-layer depth, and $L=1000 \mathrm{~m}$.

During the spin-up period, the flow is highly unsteady. For example, partial flow blocking upstream of the mountain rapidly reduces the upstream Froude number and increases the upstream layer height. This unsteadiness at the very beginning of the simulation introduces difficulties in determining the most realistic setup a priori. Consequently, we performed several simulations with different initial conditions - i.e. different initial upstream Froude numbers and layer heights - from which we chose the most realistic one according to the following criteria applied to the quasi-steady-state solution: a final upstream Froude number and layer height close to that of the 12 UTC profile listed in Table II; and a difference between upstream and downstream reservoir heights close to that of the RAMS simulation shown in Figure 9(c,d). This reservoir-height difference can be estimated from the drop of the $290 \mathrm{~K}$ isentrope between the left and right boundary of the cross-section shown, which is approximately $1 \mathrm{~km}$. The difference between the reservoir heights is partly caused by the synopticscale pressure difference across the mountain, with a lower reservoir height downstream towards the cyclone and a higher reservoir height upstream towards the highpressure system (see Figure 1).

The most realistic SWM simulation is represented in Figure $9(\mathrm{e}, \mathrm{f})$, which shows the local Froude number and the fluid-layer height along the same two vertical cross-sections as in Figure 9(a)-(d). In both transects, the flow is subcritical $(F<1)$ upstream of the crest (which corresponds to the location of the pass) and supercritical $(F>1)$ along the downstream slope of the coastal barrier. This flow transition is associated with a sharp descent of the layer height and a flow acceleration. The occurrence of a hydraulic jump on the leeward side of the mountain indicates a rapid transition back into a subcritical state. In near-perfect agreement with the RAMS simulation, the jump in the transect through Delnička Vrata (A1-A2) is situated slightly upstream of the coast, while at Vratnik Pass (B1-B2) the jump has propagated and finally settled several kilometres downstream of the coast. Consequently, winds close to the coast are weaker in $\mathrm{A} 1-\mathrm{A} 2$ than in $\mathrm{B} 1-\mathrm{B} 2$. In $\mathrm{A} 1-\mathrm{A} 2$, however, near the mountains of Cres Island at $x \approx 100 \mathrm{~km}$, the flow accelerates into a supercritical state again; whereas in B1-B2 the flow at $x>100 \mathrm{~km}$ is rather weak. The difference in the far-downstream flow behaviour between these two transects agrees perfectly with the situation depicted by the RAMS simulation (Figure 9(c,d)), and can be understood from a closer inspection of Figure 2. The southwestern part of the transect B1-B2 crosses a broad wake that has become established downstream of the island of Rab to the lee of the northern Velebit range. Therefore the jet emanating from Vratnik Pass is not aligned quite parallel with B1-B2. Instead, the Vratnik jet emanates from the gap at a slight angle to $\mathrm{B} 1-\mathrm{B} 2$, i.e. non-orthogonal to the mean orientation of the ridge axis, and subsequently merges with a broad zone of strong winds downstream of Cres Island. It appears that horizontal flow confluence occurring between the southern tip of Istria and the bent shear line formed by the cyclonic curved Vratnik jet is part of the reason for the formation of this broad jet region (see Figure 2(b)).

The effect of downstream orography on the bora flow structure can easily be determined by running the SWM with several different modified orographies. The mountains of Cres Island, although not very high, affect the flow locally. This is illustrated in Figure 9(e) by a flow transition near two peaks on Cres Island, at $x \approx 100 \mathrm{~km}$ and $x \approx 120 \mathrm{~km}$. In a simulation that uses a modified terrain without Cres Island (not shown), no flow transition occurs in that region. The strongest impact can be observed when the peninsula of Istria is removed. In such a simulation (not shown), the wake downstream of Delnička Vrata in A1-A2 is less pronounced, since the jump has propagated further downstream towards Krk Island than in the reference run. Thus, the existence of the peninsula of Istria weakens the bora flow in the northern part of the Kvarner Bay. Furthermore, without Istria the bora jet downstream of Cres Island is much broader, and less packed into a single straight jet.

\subsection{Vertical flow structure parallel to the Dinaric Alps}

Figure 10(a,b) shows the simulated flow structure of the RAMS reference run (grid 5) in a vertical cross-section parallel to the coastal mountain range, and therefore perpendicular to the average bora flow. This transect, indicated as $\mathrm{C} 1-\mathrm{C} 2$ in Figure 2(a), is oriented from northwest to southeast. Its northwestern part is positioned a few kilometres off the shoreline, and its southeastern part passes the Velebit range. The $\mathrm{C} 1-\mathrm{C} 2$ transect was flown by the DLR Falcon aircraft from $\mathrm{C} 2$ to $\mathrm{C} 1$ in the course of a so-called 'low approach' (The aircraft descends towards the airport, passes the runway at low altitude without 
(a)

$$
\text { RAMS bora110, Pot. Temp. (K), Wspd (m/s), }
$$
04-Apr-2002 08 UTC

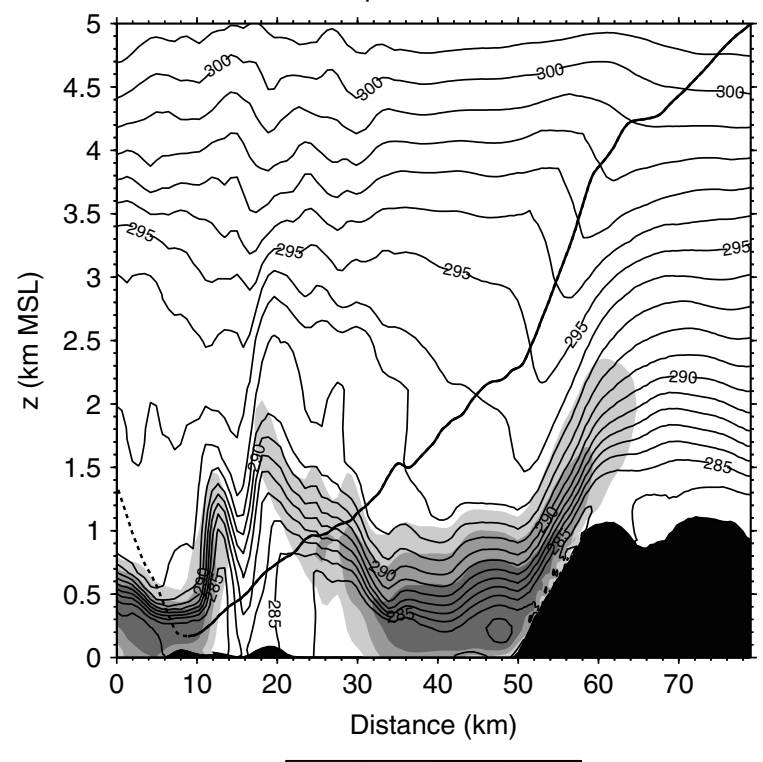

(c)

$$
\begin{array}{lllll}
10 & 15 & 20 & 25 & 30
\end{array}
$$

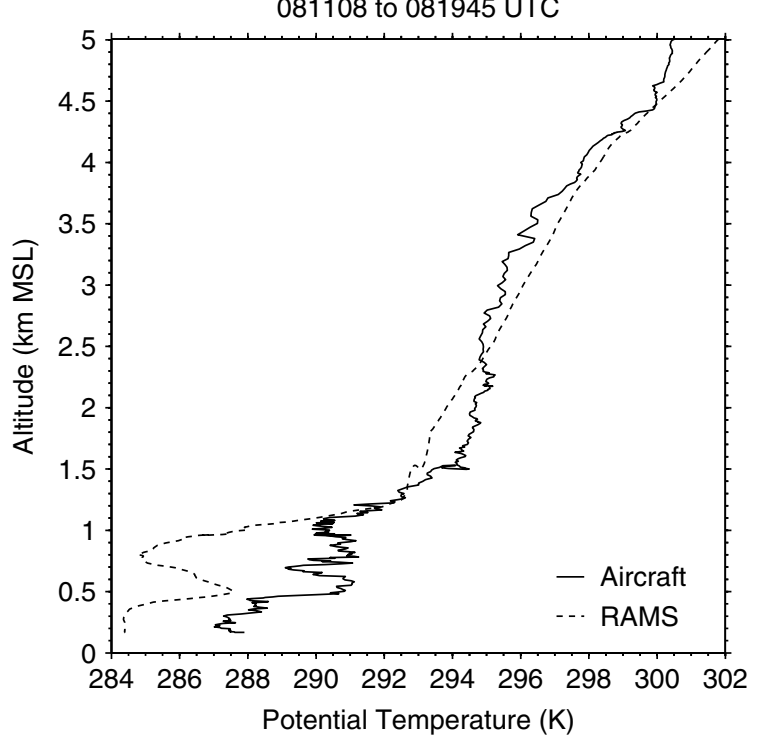

(b) RAMS bora110, Turbulent Kinetic Energy $\left(\mathrm{m}^{2} / \mathrm{s}^{2}\right)$, 04-Apr-2002 08 UTC

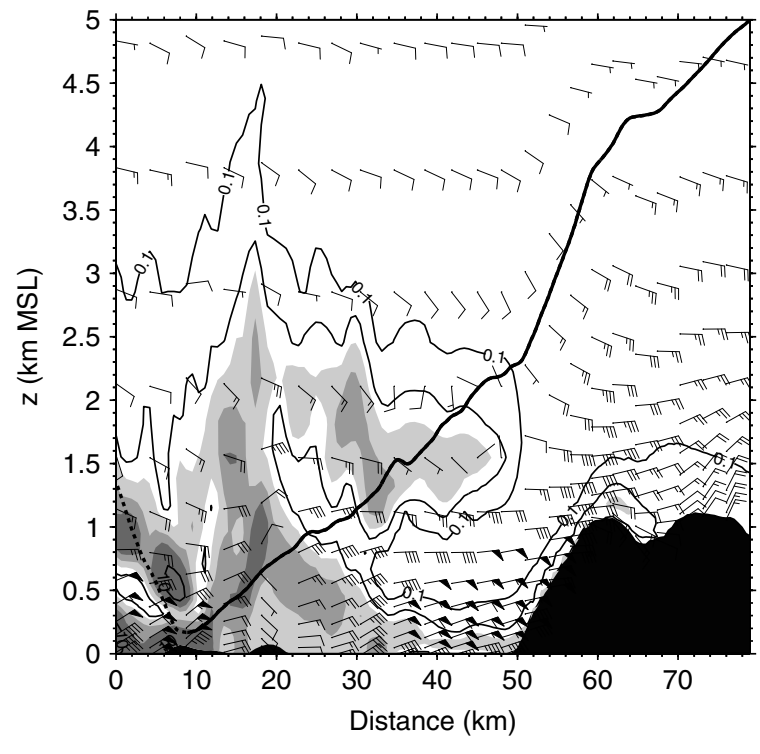

\begin{tabular}{lllll}
\hline 0 & 2 & 4 & 6 & 8
\end{tabular}

(d)

RAMS 04-Apr-2002 08 UTC, DLR Falcon 081108 to 081945 UTC

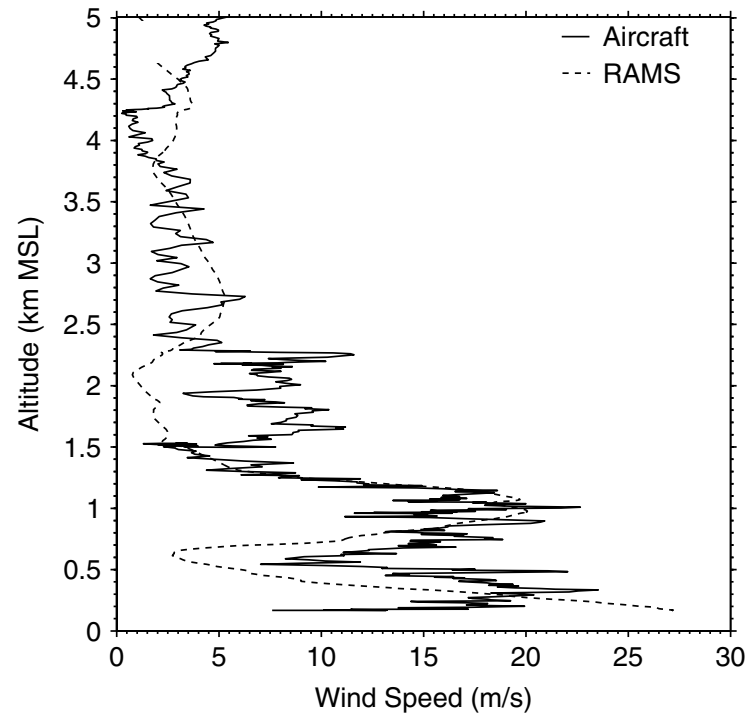

Figure 10. (a,b) Vertical transect parallel to the Dinaric Alps along C1-C2 from northwest to southeast, as indicated in Figure 2(a). (c,d) Profile of the atmosphere along a slanted flight path indicated as a thick solid line in (a) and (b) at approximately 08 UTC on 4 April 2002. RAMS reference simulation (grid 5) illustrated as: (a) contour lines of potential temperature with $1 \mathrm{~K}$ increments, and grey-shaded contours of horizontal wind speed with $5 \mathrm{~ms}^{-1}$ increments; and (b) grey-shaded contours of TKE with $2 \mathrm{~m}^{2} \mathrm{~s}^{-2}$ increments (with black contour lines for $0.1 \mathrm{~m}^{2} \mathrm{~s}^{-2}$, $1 \mathrm{~m}^{2} \mathrm{~s}^{-2}$ and $10 \mathrm{~m}^{2} \mathrm{~s}^{-2}$ ), and wind barbs for the horizontal wind direction and speed. Half barbs, full barbs and triangles denote winds of $2.5 \mathrm{~ms}^{-1}, 5 \mathrm{~ms}^{-1}$ and $25 \mathrm{~ms}^{-1}$ respectively. A barb pointing upward (rightward) indicates northerly (easterly) winds. Observed (solid line, 08:11-0820 UTC) and simulated (dashed line, 08 UTC, grid 5) slanted profiles of (c) potential temperature and (d) horizontal wind speed.

landing, and ascends again.) to the airport of Rijeka at around 08 UTC on 4 April 2002. It is important to note that the runway is oriented perpendicularly to the bora wind direction. The slanted aircraft trajectory is shown as a solid line in Figure 10(a,b). The corresponding in situ measurements, as well as RAMS model data along this aircraft path, represent pseudo-vertical soundings, and are shown in Figure 10(c,d).

The most striking features of Figure 10(a,b) are the two low-level jets for $0 \mathrm{~km} \lesssim x \lesssim 10 \mathrm{~km}$ and $30 \mathrm{~km}$ $\lesssim x \lesssim 50 \mathrm{~km}$. The former is the jet emanating from Delnička Vrata, and the latter is the Vratnik jet. The jet-layer depth varies between $500 \mathrm{~m}$ and $1000 \mathrm{~m}$, and jet winds exceed $30 \mathrm{~ms}^{-1}$. The near-neutral stratification between about $1000 \mathrm{~m}$ and $3000 \mathrm{~m} \mathrm{AMSL}$ on top of these two jets is the result of overturning gravity waves. In the wave-breaking region, winds are generally weak, and blow from coastline-parallel (southeast) or even reversed (southwest) directions. In between these two surface jets, for $10 \mathrm{~km} \lesssim x \lesssim 30 \mathrm{~km}$, a cold 
dome encompasses a wake region with weak low-level winds. Isentropes are located approximately $1000 \mathrm{~m}$ higher over the wake than over the adjacent jet areas. This cold dome represents a wave-induced rotor, and is discussed in more detail in Section 5. Subgrid-scale TKE in Figure 10(b) is especially high in regions of low stability or strong vertical wind shear: that is, in the wave-breaking and the rotor region, as well as near the surface where values of $2-8 \mathrm{~m}^{2} \mathrm{~s}^{-2}$ and higher are found.

Figure $10(\mathrm{c}, \mathrm{d})$ shows the slanted observed and simulated profiles along the aircraft trajectory. The aircraft starts to descend at around $5 \mathrm{~km}$ AMSL, and passes through a stably-stratified atmosphere with winds less than $5 \mathrm{~ms}^{-1}$. Between $3.5 \mathrm{~km}$ and $1.5 \mathrm{~km}$ AMSL, it encounters the near-neutrally-stratified wave-breaking layer, and it enters the inversion layer at around $1.5 \mathrm{~km}$ AMSL. Below the inversion layer, the aircraft passes a highly turbulent jet-wind layer characterized by strong fluctuations in several measured quantities. Wind-speed and potential-temperature fluctuations in the $1 \mathrm{~Hz}$ dataset have typical magnitudes of $5 \mathrm{~ms}^{-1}$ and $0.8 \mathrm{~K}$ respectively. Turbulence quantities, such as TKE, have not been analysed so far. The structural agreement between the observed and simulated profiles is remarkably good, except for a cold bias in the bora layer below $1 \mathrm{~km}$ AMSL, which is consistent with results discussed in Section 4.1.2 and may point to underestimation of turbulent mixing by the model. Observations and simulations show a distinct local wind-speed minimum in the jetwind profile at about $0.5 \mathrm{~km}$ AMSL, with winds less than $10 \mathrm{~ms}^{-1}$. In this part of the profile, the aircraft passes the rotor region and experiences a sudden drop in wind speed and a change in wind direction (see Figure 10(a,b)). Approximately $2 \mathrm{~km}$ before reaching the runway, the aircraft enters the jet flow again, and experiences crosswinds of up to $25 \mathrm{~ms}^{-1}$.

The hazardous effects of mountain winds on aircraft operation has been discussed by Carney et al. (1996). Khatwa and Helmreich (1999) found that adverse wind conditions (i.e. strong crosswinds, tail winds or wind shear) had been involved in about 33\% of 76 approachand-landing accidents and serious incidents worldwide in the years 1984-1997. In Figure 10(d), winds in the lowest $100 \mathrm{~m}$ above ground level blow perpendicular to the aircraft trajectory at $10-20 \mathrm{~ms}^{-1}$. Gusts at Krk Bridge are even stronger, with speeds of $30-35 \mathrm{~ms}^{-1}$ (see Figure 3). Similar strong crosswinds have been responsible for approach-and-landing accidents in the past (e.g. FSF, 1999, 2000). Atmospheric rotors, i.e. horizontal-axis vortices, have been considered as potential contributors to aircraft accidents at upper levels during the passage of mountains (e.g. Clark et al., 2000), as well as at low levels during final approach (e.g. FSF, 1993; Darby and Poulos, 2006; Doyle and Durran, 2007). To our knowledge, off-ground aircraft accidents during bora have not yet been recorded. However, according to the Aviation Safety Network database (http://aviation-safety.net/database), an Antonov 2R aircraft was flipped upside down by a strong bora storm on 23 November 2005 while parked at Rijeka airport.

\section{Wave-induced rotor and hydraulic jump}

In the light of the aviation hazard of mountain winds discussed above, we will now focus on a more detailed analysis of the flow structure in the vicinity of Rijeka airport on Krk Island during the time of the bora breakthrough. Specifically, we will explore the waveinduced rotor and the bora jet that an aircraft would have to pass when approaching the airport. We have already noted, in Section 4, the very transient behaviour of the flow structure at the time of the breakthrough. Therefore, in other bora cases the picture of the flow at a specific instant may differ from the one below.

\subsection{Small-scale flow structure}

Figure 11 illustrates the flow structure as depicted by the highest-resolution model domain 6 at 07 UTC. Figure 11(a) shows a plan view at $300 \mathrm{~m}$ AMSL, and Figures 11(b,c,d) show three vertical transects with three different orientations. The plan view illustrates the jet through Delnička Vrata ('DV'), which has already passed Krk Bridge ('BRI'), the northern tip of Krk Island, and the airport at Rijeka. In fact, the airport is located close to a shear line formed by this gap jet and the wake to the lee of the Kapela mountains. This low-level shear line is impressively seen in transect D1-D2 (Figure 11(b)), which is aligned parallel to the coastline. At $x \approx 15 \mathrm{~km}$, the wind speed changes by about $20 \mathrm{~ms}^{-1}$ and the direction by up to $180^{\circ}$ within a narrow zone of less than $5 \mathrm{~km}$. The wake, for $15 \mathrm{~km} \lesssim x \lesssim 25 \mathrm{~km}$, represents a wave-induced rotor. Such a vortex, with a horizontal rotation axis aligned parallel to the mountain ridge, is formed by boundary-layer separation underneath trapped mountain lee waves as a result of an adverse pressure gradient induced by the first wave crest (Doyle and Durran, 2002).

The existence of the rotor underneath a wave crest is also documented in the transect F1-F2 in Figure 11(d), which is aligned downstream of the southeastern edge of the mountain gap and is a subsection of the aircraft leg A1-A2. At any specific instant, such a rotor does not typically show well-organized and relatively laminar rotation, but is characterized by embedded sub-rotors (Doyle and Durran, 2007). Our model resolution is presumably not sufficiently high to resolve these subrotors. The size of the main rotor at the instant shown is approximately $2 \mathrm{~km}$ in the vertical direction, $5 \mathrm{~km}$ along the stream and $10 \mathrm{~km}$ across the stream.

The transect E1-E2 in Figure 11(c) illustrates the flow through the centre of the gap. There, the flow structure is clearly different from that of F1-F2. Instead of a rotor, the bora front in E1-E2, i.e. the leading edge of the gap jet, is characterized by a hydraulic-jump-like transition from strong to weak winds. The mountain gap 
(a)

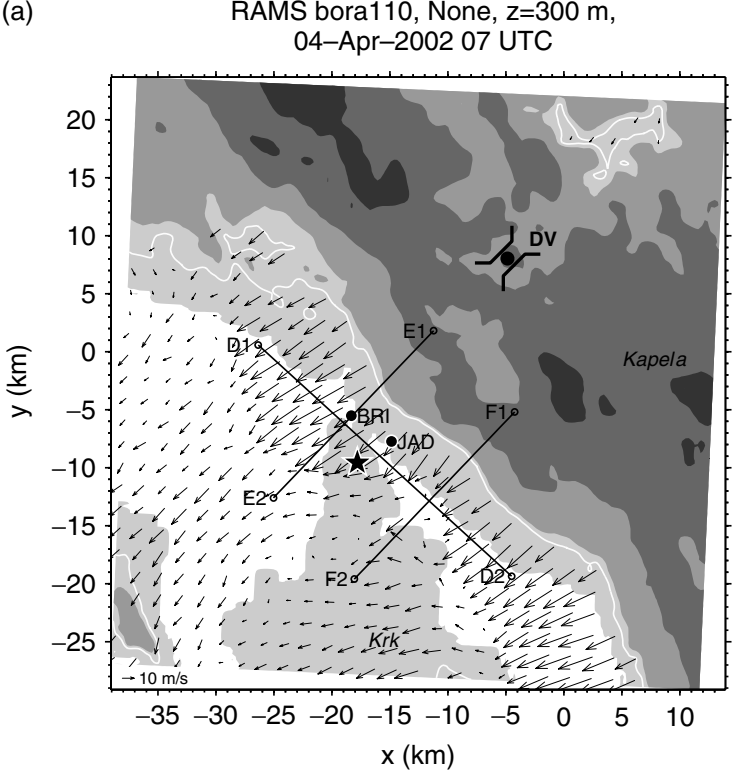

(c)

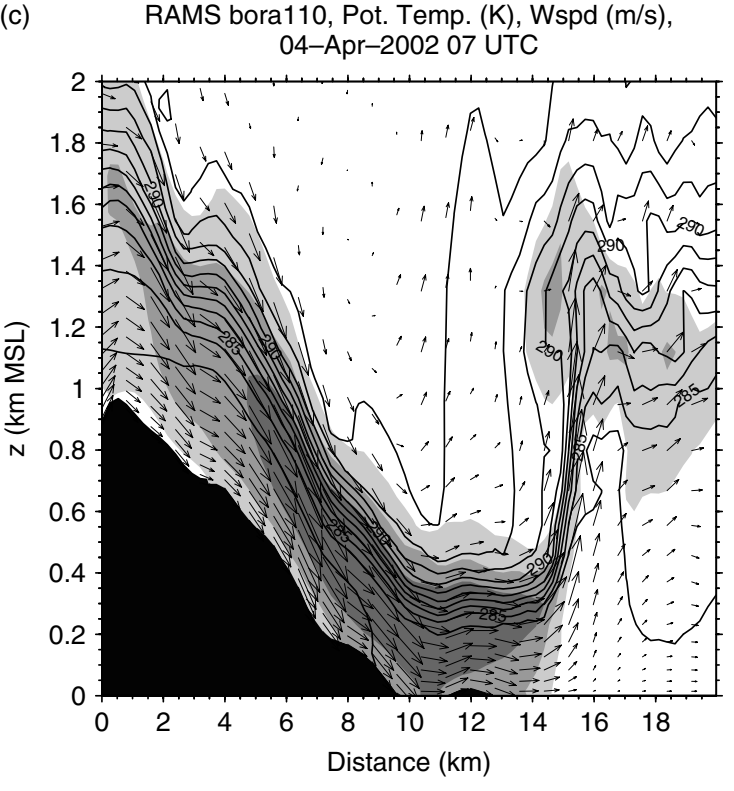

(b)

RAMS bora110, Pot. Temp. (K), Wspd (m/s), 04-Apr-2002 07 UTC

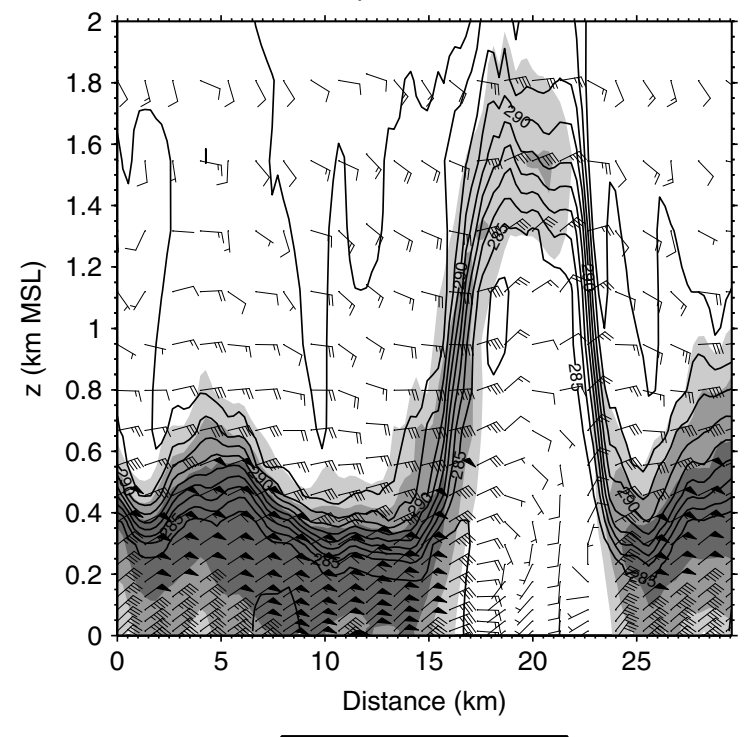

(d)

RAMS bora110, Pot. Temp. (K), Wspd (m/s), 04-Apr-2002 07 UTC

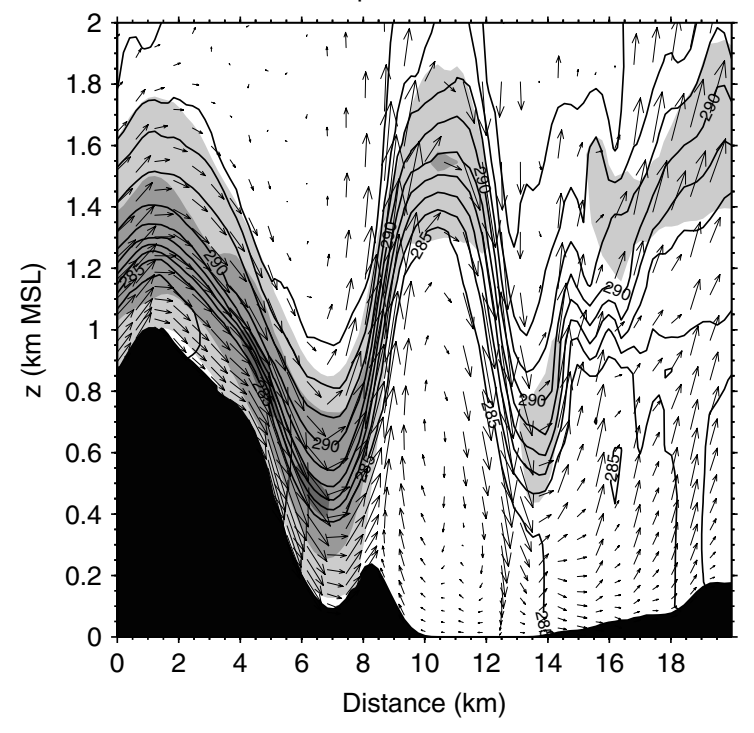

$\begin{array}{lllll}10 & 15 & 20 & 25 & 30\end{array}$

Figure 11. Flow structure in the vicinity of Rijeka airport downstream of the mountain gap Delnička Vrata ('DV') at 07 UTC on 4 April 2002, as represented in model domain 6 of the RAMS reference run. (a) Plan view of horizontal wind vectors at $300 \mathrm{~m}$ AMSL, as in Figure 2(b). Elevation contours of the terrain indicated by grey shading are as in Figure 2(a). Rijeka airport on Krk Island is indicated by a star. (b,c,d) Vertical transects: (b) parallel to the coastline along the leg D1-D2; (c) perpendicular to the coastline along the leg E1-E2; (d) along F1-F2. The transect F1-F2 is a subsection of the aircraft transect A1-A2 (see Figure 2(a)). Contour lines of potential temperature have $1 \mathrm{~K}$ increments, and grey-shaded contours of horizontal wind speed have $5 \mathrm{~ms}^{-1}$ increments. In (b), wind barbs for the horizontal wind direction and speed are as described in Figure 10(b). In (c) and (d), wind vectors show the components parallel to the cross-section.

appears to favour an earlier breakthrough of the bora with the formation of a hydraulic jump, while the adjacent higher terrain of the ridge promotes flow separation with the formation of a rotor and consequently a delayed breakthrough.

A small hill near the coast in Figure 11(d) may favour flow separation. However, the boundary layer also separates downstream of the northwestern edge (not shown) of the mountain gap (see Figure 11(a)), where the slope is on average less steep and contains no secondary hill. In Figure 11(c), a wedge of air of higher potential temperature, formed by wave-breaking on top of the bora inversion, corresponds to the observed local pressure minimum documented in Figure 4(c).

\subsection{Turbulence}

The turbulence structure of the hydraulic jump and of the rotor are shown in Figure 12 (a) and (b) respectively. Highest TKE values exceeding $10 \mathrm{~m}^{2} \mathrm{~s}^{-2}$ are found in 
(a)

$$
\text { RAMS bora110, Turbulent Kinetic Energy }\left(\mathrm{m}^{2} / \mathrm{s}^{2}\right) \text {, }
$$
04-Apr-2002 07 UTC

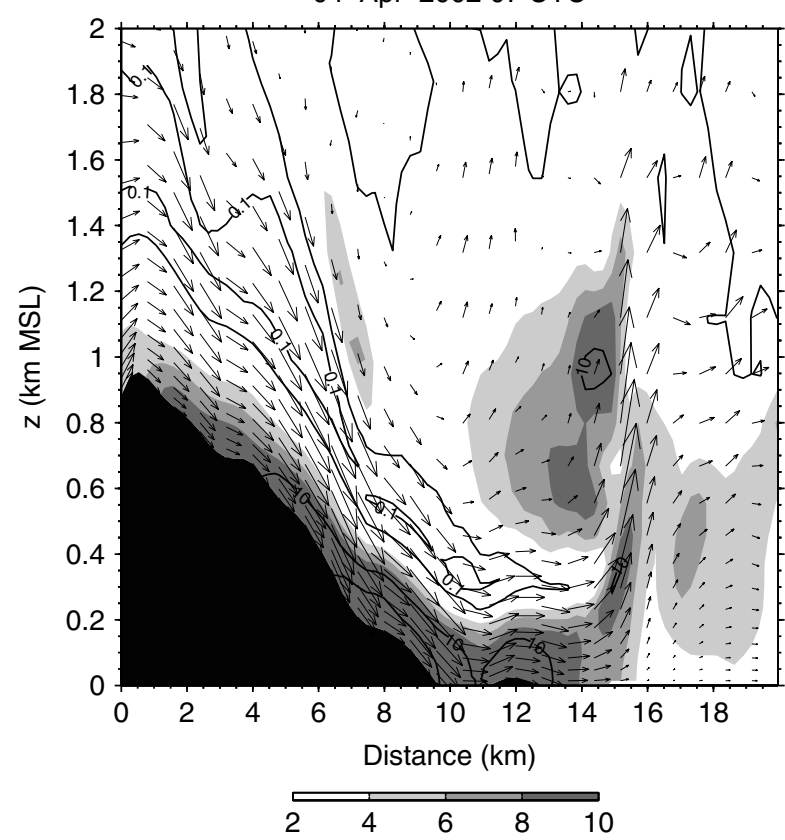

(b) RAMS bora110, Turbulent Kinetic Energy $\left(\mathrm{m}^{2} / \mathrm{s}^{2}\right)$,

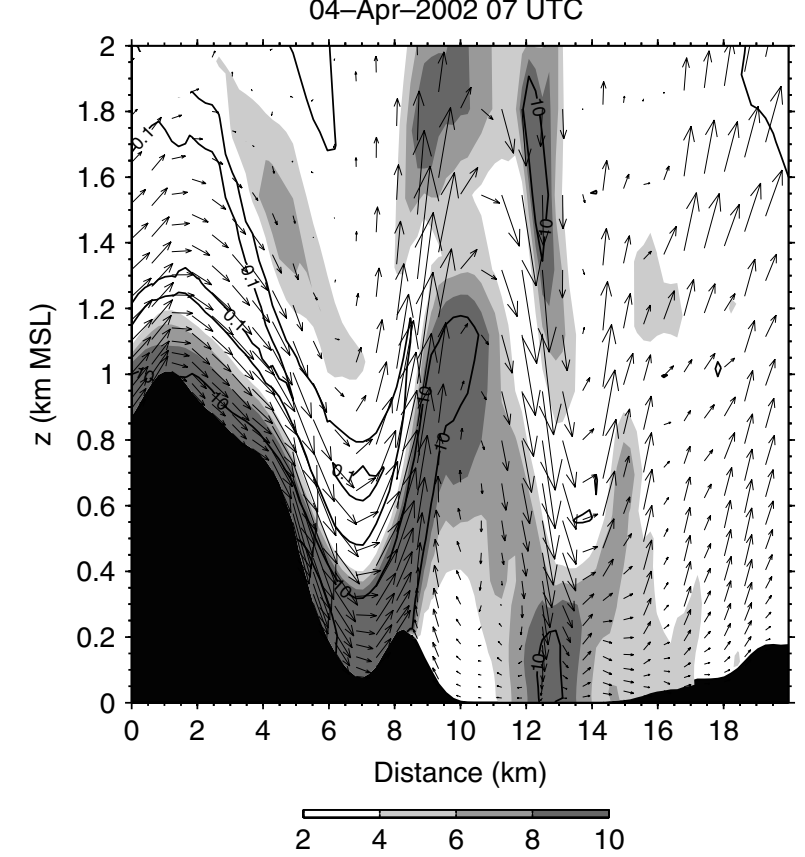

Figure 12. As Figure 11(c,d), but for TKE along the transects (a) E1-E2 and (b) F1-F2. Grey-shaded contours indicate $4 \mathrm{~m}^{2} \mathrm{~s}^{-2}, 6 \mathrm{~m}^{2} \mathrm{~s}^{-2}$ and $8 \mathrm{~m}^{2} \mathrm{~s}^{-2}$; black contour lines indicate $0.1 \mathrm{~m}^{2} \mathrm{~s}^{-2}, 1 \mathrm{~m}^{2} \mathrm{~s}^{-2}, 10 \mathrm{~m}^{2} \mathrm{~s}^{-2}$ and $15 \mathrm{~m}^{2} \mathrm{~s}^{-2}$.

a near-surface layer about $200 \mathrm{~m}$ deep in which TKE is mechanically produced by surface friction. Moderate TKE values, of $4-6 \mathrm{~m}^{2} \mathrm{~s}^{-2}$, are found on top of the bora flow, where wind shear (decreasing wind speed with increasing height) and low static stability above the inversion layer lead to low Richardson numbers. Lowlevel wave breaking causes high TKE, up to $10 \mathrm{~m}^{2} \mathrm{~s}^{-2}$, especially close to the hydraulic jump (12 km $\lesssim \lesssim$ $15 \mathrm{~km}$ in Figure 12(a)). The jump itself can be identified by a narrow, vertically-aligned band of high TKE. For wave-induced rotors, Doyle and Durran (2002) found that surface friction produces a sheet of horizontal vorticity, which is lifted vertically into the lee wave at the separation point and is carried, at least in part, into the rotor itself. This horizontal-vorticity structure is in agreement with the turbulence structure shown in Figure 12(b). Horizontal vorticity, combined with low stability, is the primary source for TKE in our case. Consequently, a sheet of TKE is lifted off the surface and subsequently advected into the lee wave, which results in the highest TKE, exceeding $10 \mathrm{~m}^{2} \mathrm{~s}^{-2}$, especially along the upstream edge and near the top of the lee wave. Both this structure and the TKE magnitudes are in good agreement with the TKE fields shown by Doyle and Durran (2002).

\subsection{Temporal evolution}

The flow depicted in Figure 11 is far from being steady. It is merely a snapshot near the time of the breakthrough. The transient nature of the flow becomes obvious in Figures 13 and 14. Figure 13 shows the model transect F1-F2 at 03 and 09 UTC, which should be compared with the 07 UTC transect in Figure 11(d). While the simulated rotor is nearly stationary during the night, it starts to propagate downstream in the morning between 07 and 08 UTC; this is associated with the breakthrough of the bora at the coast as upstream background flow conditions change. Aerosol back-scatter lidar measurements cannot fully prove the existence of a rotor, since they lack wind information, but they can illuminate the general lee-wave structure and the timing of the propagation. Figure 14 shows these observations for two snapshots, at about $20 \mathrm{~min}$ before and after 07 UTC. As a result of strong turbulent mixing in the boundary layer, the back-scatter signal is close to the detection limit, which consequently allows only a restricted qualitative comparison with the simulation. Notice that the grey scale and the wavelength channel $(1064 \mathrm{~nm})$ have been chosen differently from those in Figure 9, in order to highlight the top of the bora flow (see the solid line in Figure 14). The earlier of the two snapshots (Figure 14(a)) shows a wave structure similar to that in Figure 11(d), with flow separation near a small hill to the lee of the main ridge and the first wave crest located near the coast. Approximately $40 \mathrm{~min}$ later, this wave crest has propagated about $4 \mathrm{~km}$ downstream, and consequently the bora front has advanced past the coast (Figure 14(b)). More than an hour later, the model indicates that the wave crest has reached the island of Krk (Figure 13(b)). The hydraulic jump at the centre of the gap is nearly stationary, and is located close to the coast throughout the night (not shown), subject only to the oscillation discussed in Section 3.3.1. It starts to propagate downstream at around 05 UTC, i.e. about two hours earlier than the rotor. 
(a)

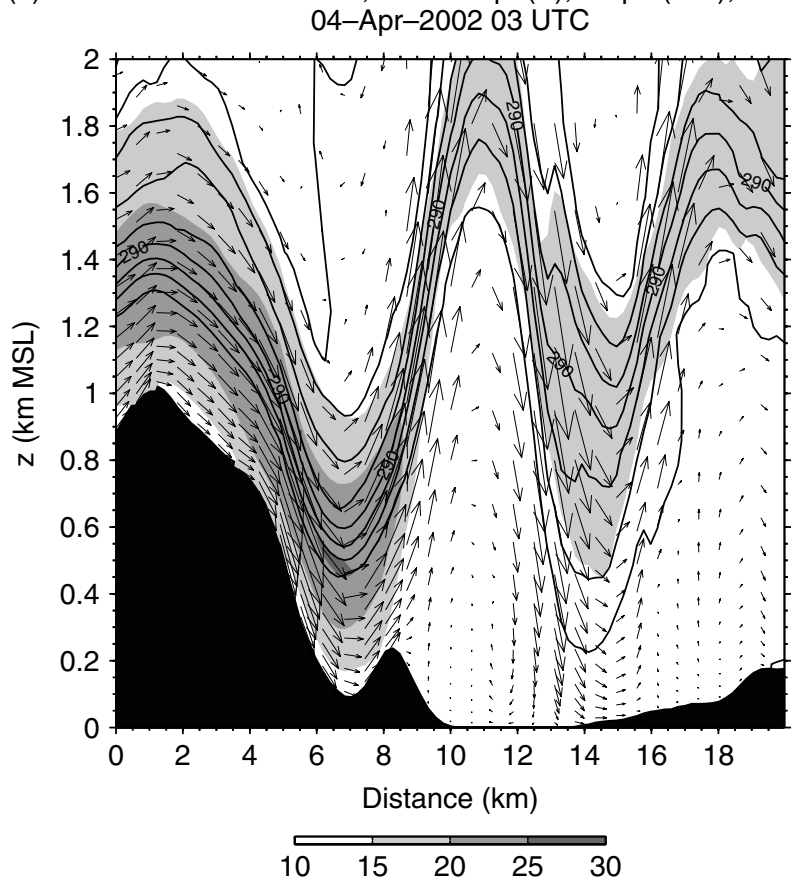

(b)

RAMS bora110, Pot. Temp. (K), Wspd (m/s),

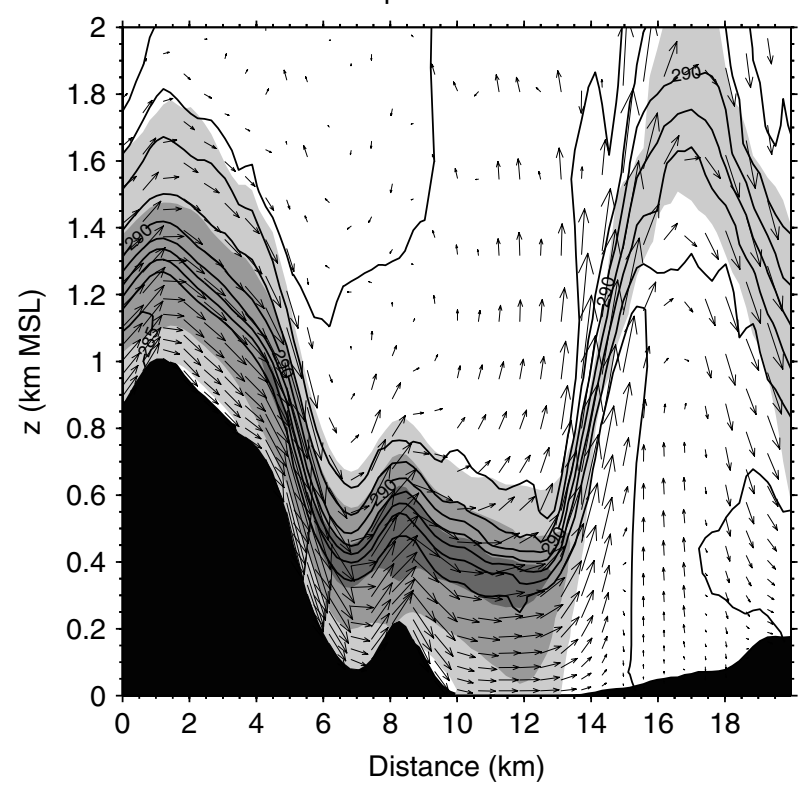

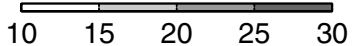

Figure 13. As Figure 11(d) for transect F1-F2, but at (a) 03 UTC and (b) 09 UTC.

(a)

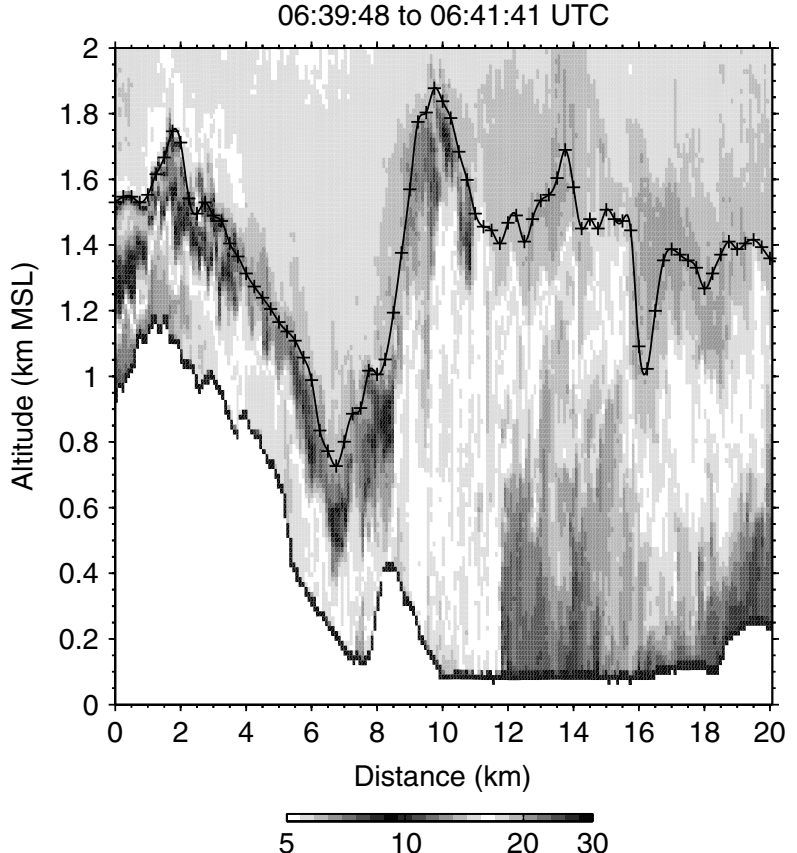

(b)
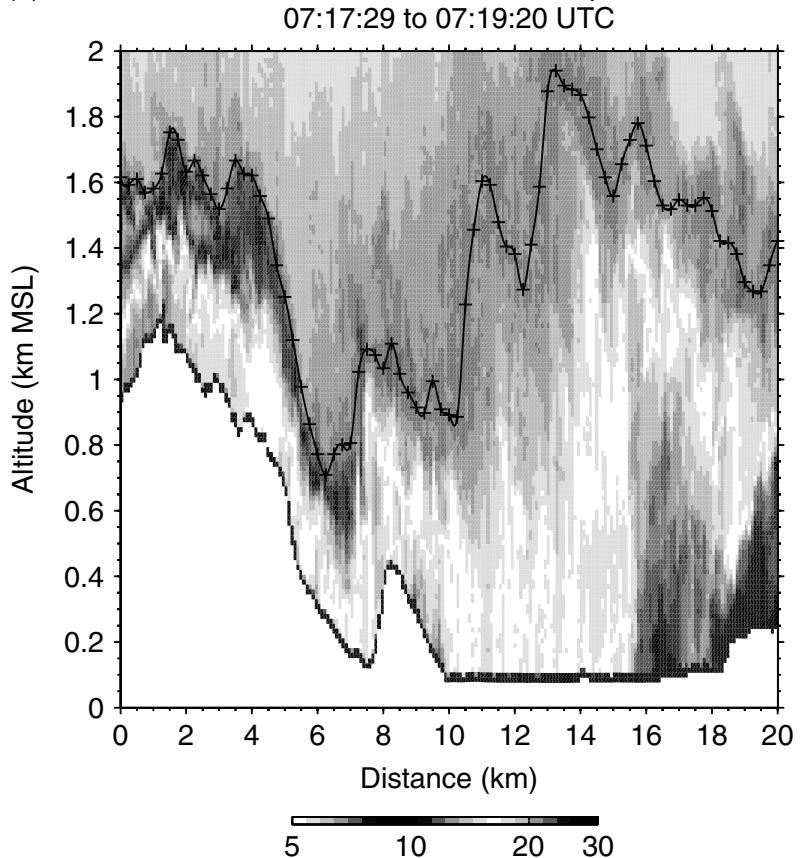

Figure 14. Range-corrected back-scatter intensity (arbitrary units) at $1064 \mathrm{~nm}$ for the vertical cross-section F1-F2 (see Figure 11(a)), on 4 April 2002: (a) 06:40-06:42 UTC; (b) 07:17-07:19 UTC. Notice that the grey scale is logarithmic and passes through dark shadings twice. The top of a particular aerosol layer (corresponding approximately to the $291 \mathrm{~K}$ isentrope) has been manually highlighted as a black line with markers.

The high temporal and spatial variability of the flow near the time of the bora breakthrough clearly poses a challenge to local weather forecasters, and implies a certain risk for air traffic. At the instant of 07 UTC (see Figures 11 and 12), an aircraft approaching the airport from the southeast would fly parallel to the transect D1-D2 (from D2 to D1), first passing the rotor at a few hundred metres above ground level and finally encountering the bora jet just before touchdown. However, at a later instant the rotor may have propagated further downstream. At that time, the aircraft conducting its final approach would not encounter the rotor, but would fly through steadier, though still strong and turbulent, crosswinds. Such rapid changes in flow direction, 
and their potential impact on landing conditions, were also documented in a rotor case study by Darby and Poulos (2006).

\section{Sensitivity to turbulence parametrization}

In this section we will examine the sensitivity of the flow structure to the turbulence closure scheme. We will show that the time of the bora breakthrough, the amplitude of the mountain lee waves and the strength of the bora inversion are very sensitive to the type and parameter settings of the turbulence parametrization. This is in contrast to previous studies of gravity waves and rotors which observed no distinct sensitivity of the model results to the turbulence parametrization (e.g. Vosper, 2004; Hertenstein and Kuettner, 2005; Jiang et al., 2007). However, these papers did not study the sensitivity to the turbulence parametrization in a systematic way, and therefore their conclusions in this respect might be limited.

Figure 15 illustrates the vertical flow structure at 07 UTC along two transects, one to the lee of the centre and one at the edge of Delnička Vrata. Results are shown from the highest-resolution model grid 6 , for three simulations with three different turbulence parametrizations. These two transects should be compared with the reference run shown in Figure 11(c,d). The turbulence closure schemes are explained in Section 2.1, and summarized in Table I. The reference run uses the DD scheme in grid 6, which is presumably the most appropriate scheme among those presented here for very high grid resolutions. The MY-SM scheme (see Figure 15(a,b,d,e)) assumes complete decoupling of horizontal and vertical diffusion. It is therefore more appropriate for relatively large horizontal mesh sizes of $\Delta x \gg 1 \mathrm{~km}$, which would justify the use of anisotropic diffusion. Nevertheless, similar schemes are still used in studies of downslope windstorms for small horizontal grid spacings $\Delta x \ll 1 \mathrm{~km}$ (e.g. Doyle and Durran, 2002; Zängl and Gohm, 2006; Zängl et al., in press). The iso-SM scheme (see Figure $15(\mathrm{c}, \mathrm{f})$ ) is more appropriate for $\Delta x \approx \Delta z$.

The results in Figures 15(a,b,c) and 11(c) for the flow through the centre of the gap reveal that the location of the bora front is highly sensitive to the turbulence parametrization. The time of the bora breakthrough is therefore also affected. According to Figure 3, the bora

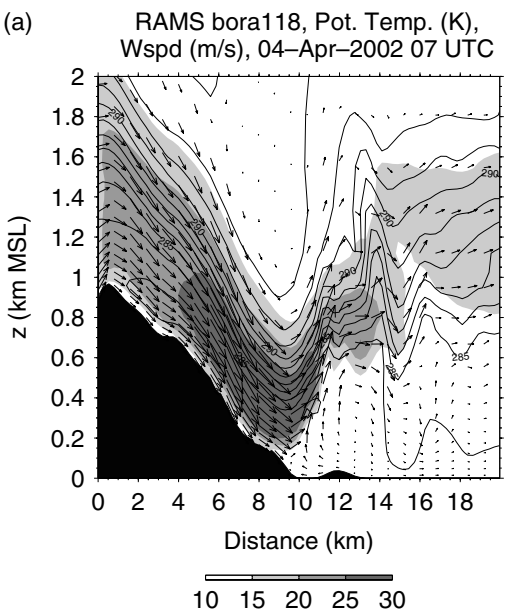

(d) RAMS bora118, Pot. Temp. (K), Wspd (m/s), 04-Apr-2002 07 UTC

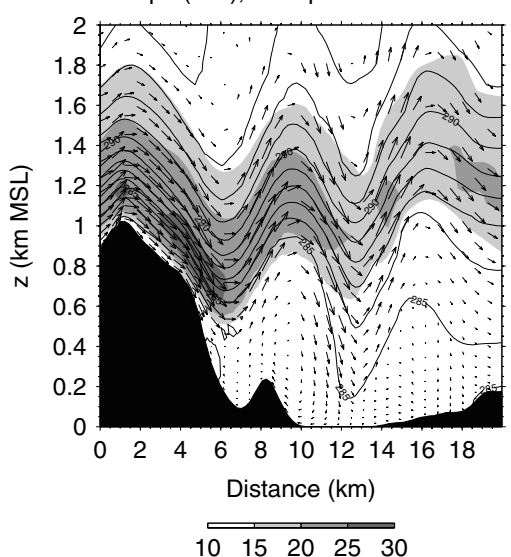

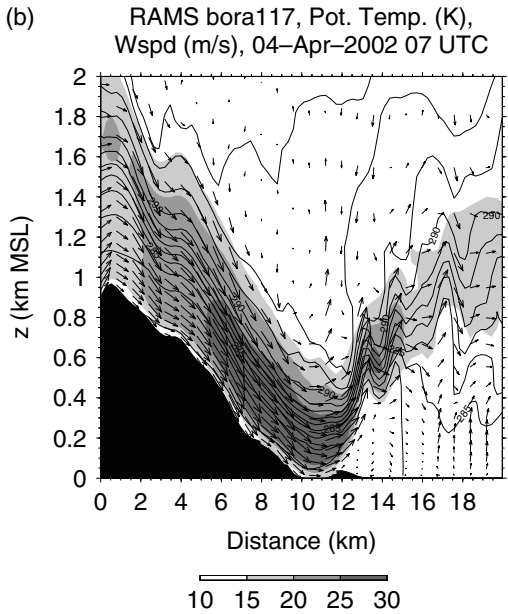

(e) RAMS bora117, Pot. Temp. (K),

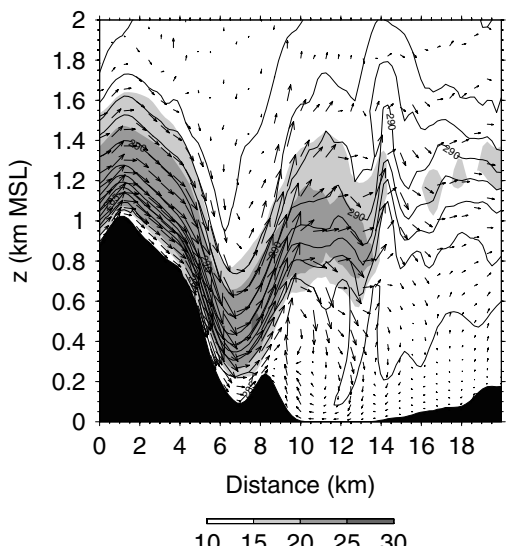

(c) RAMS bora122, Pot. Temp. (K) Wspd (m/s), 04-Apr-2002 07 UTC

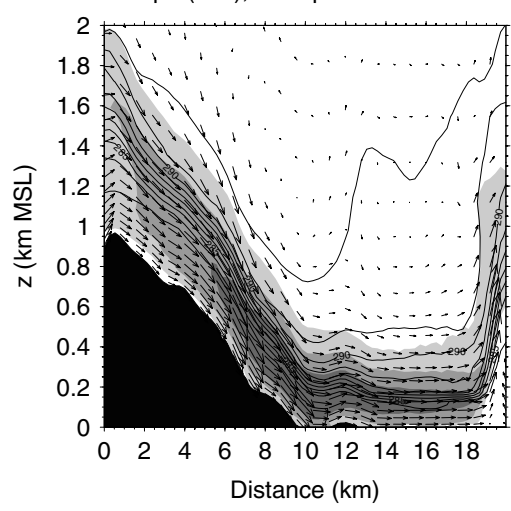

$1 0 \longdiv { 1 5 2 0 \quad 2 5 \quad 3 0 }$

(f) RAMS bora122, Pot. Temp. (K) Wspd (m/s), 04-Apr-2002 07 UTC

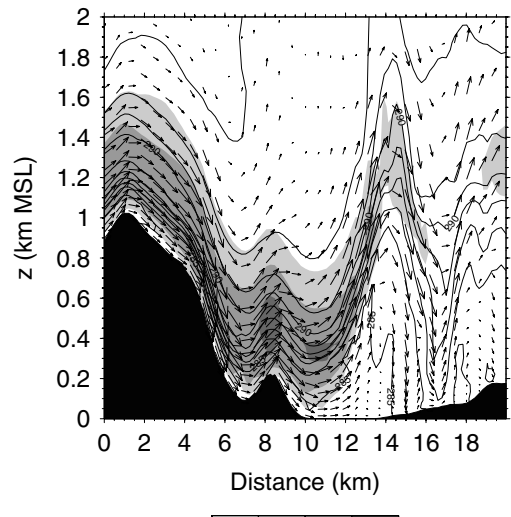

$10 \quad 1520 \quad 25 \quad 30$

Figure 15. As Figure 11(c,d), but for different turbulence parametrization schemes: vertical cross-sections (a,b,c) E1-E2 and (d,e,f) F1-F2 (see Figure 11(a)) at 07 UTC on 4 April 2002; simulations (a,d) MYSM-135-10, (b,e) MYSM-320-01 and (c,f) ISOSM-320-01. See text and Table I for further explanation. 

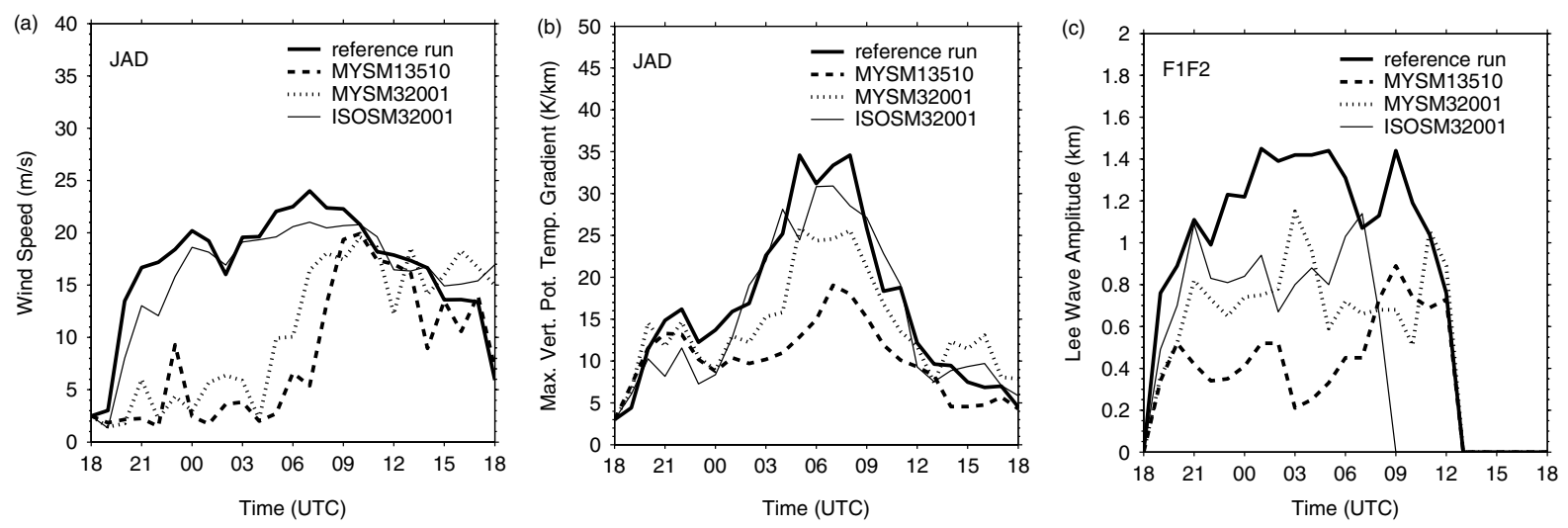

Figure 16. Comparison of (a) near-surface wind speed, (b) maximum vertical gradient of potential temperature in the bora inversion layer, and (c) lee-wave amplitude, between four different simulations: reference run (thick solid line), MYSM-135-10 (dashed line), MYSM-320-01 (dotted line), and ISOSM-320-01 (thin solid line). A $24 \mathrm{~h}$ period starting at 18 UTC on 3 April 2002 is shown. Model data in (a) and (b) are taken from the grid point at Jadranovo ('JAD'). Lee-wave amplitudes in (c) are estimated from the vertical displacement of the $290 \mathrm{~K}$ isentrope in the transect F1-F2, as shown, for example, in Figure 11(d,e,f). See text and Table I for further explanation.

front should have passed the coast more than four hours before 07 UTC. The MYSM-135-10 run predicts the front still upstream of the coast, and the MYSM-320-01 run predicts it close to the coast. In the more realistic reference simulation, the front has already passed the northern tip of Krk Island. In the ISOSM-320-01 simulation the front has almost propagated out of the subdomain shown. The difference in the time of the bora onset is also illustrated in Figure 16(a), based on the wind speed at Jadranovo. The salient feature is a $12 \mathrm{~h}$ delay of the bora breakthrough in MYSM-135-10 compared with the reference run.

In Section 4.1, we noticed that the reference run overestimates the strength of the bora inversion, and we attributed this result to a failure of the turbulence scheme. This suspicion is corroborated by the sensitivity of the maximum vertical gradient of potential temperature in the inversion layer to the type of turbulence parametrization (see Figure 16(b)). During the late night and early morning, compared with the reference run, this gradient is about $50 \%$ weaker in MYSM-135-10, about $25 \%$ weaker in MYSM-320-01, and about the same in ISOSM-320-01.

The lee wave downstream of the edge of the gap in Figures $15(\mathrm{~d}, \mathrm{e}, \mathrm{f})$ and $11(\mathrm{~d})$ is also strongly affected by the choice of the turbulence closure. The wave amplitude in MYSM-135-10 is much smaller, and the rotor circulation weaker, than in the reference run. Figure 16(c) shows that the wave amplitude in MYSM-135-10 during the night is only about one-third of the amplitude in the reference run. The wave amplitude was estimated from the vertical displacement of the $290 \mathrm{~K}$ isentrope, and represents the elevation difference between the trough and the crest of the first lee wave in transect F1-F2. A zero amplitude in Figure 16(c) around 12 UTC indicates that the wave has propagated out of the transect or changed into a hydraulic jump. In this context, it is noteworthy that Gohm and Mayr (2005) also reported an underestimation of the simulated amplitude of trapped gravity waves compared with observations. They used the same set-up as in the MYSM-135-10 run. In the MYSM-320-01 and ISOSM-320-01 simulations, the lee-wave amplitude is about two-thirds of the amplitude of the reference run, and therefore less affected. The isentropes are strongly distorted, and do not resemble a laminar wave. Nevertheless, the noisy wave field has similarities to the small-scale wave structures, with wavelengths of $1-4 \mathrm{~km}$, represented in the backscatter observations (see Figure 14). In terms of rotor types, as classified by Hertenstein and Kuettner (2005), the reference run resembles a type 1 rotor in which the inversion remains intact in the lee of the mountain. In the simulations MYSM-320-01 and ISOSM-320-01, the rotor is more of a type 2 rotor, resembling a hydraulic jump. While in the simulations of Hertenstein and Kuettner (2005), who used the DD scheme, the rotor type was determined by the strength of the wind shear in the inversion, in our runs the rotor type appears to be influenced by the choice of the turbulence parametrization scheme.

A closer inspection of our model results reveals that differences in the magnitude of the horizontal diffusion coefficient are the reason for discrepancies in the lee-wave amplitudes, bora front locations and inversion strengths. In MYSM-135-10, an essentially constant horizontal diffusion coefficient $K_{\mathrm{mh}}$ is applied everywhere in the domain. This is a result of setting $K_{\mathrm{A}}=1.0$, which obviously produces too high a threshold value $K_{\min }$ and no longer allows a deformation-sensitive calculation of $K_{\mathrm{mh}}$ (see Equation (1)). This unrealistically high horizontal diffusion is thus the reason for the observed damping of trapped gravity waves. Use of a lower $K_{\mathrm{A}}=0.1$, as in MYSM-320-01, allows Equation (1) to predict a more realistic spatial variation of $K_{\mathrm{mh}}$ as a function of the magnitude of the deformation. However, the dilemma here is that for some cases, especially for very steep terrain and weak dynamical forcing, $K_{\mathrm{A}} \gg 0.1$ is needed in order to guarantee numerical stability and suppress the growth of numerical noise. These findings are based on idealized test cases with an initially stagnant atmosphere in a steep valley (not shown). This dilemma is probably the reason for the numerical noise detected by de Wekker 
et al. (2005) in their simulations of valley winds. Compared with the MY-SM runs, the reference simulation as well as the ISOSM-320-01 run apply smaller horizontal (as well as vertical) diffusion coefficients in most parts of the domain. In the reference run, close to the surface $K_{\mathrm{mh}}$ and $K_{\mathrm{mv}}$ partly exceed $100 \mathrm{~m}^{2} \mathrm{~s}^{-1}$, whereas in the ISOSM$320-01$ run they are generally below $20 \mathrm{~m}^{2} \mathrm{~s}^{-1}$ in the lowest few hundred metres. It is conceivable that these boundary-layer diffusion coefficients are too small. There are several indications that the turbulent mixing close to the surface is too weak: the low-level cold bias detected in the reference run (see Section 4.1.2); the too-fast propagation of the bora front in ISOSM-320-01 (Figure 15(c)); and the stronger and sharper inversion in the reference run and ISOSM-320-01 compared to the MY-SM simulations (see Figure 16(b)).

\section{Summary and conclusions}

We have presented a detailed analysis of a strong Adriatic bora that occurred on 4 April 2002. We have focused on the onset phase of the windstorm, which was characterized by a highly transient and three-dimensional wind field downstream of a mountain gap in the vicinity of an airport. Airborne as well as ground-based observations, together with numerical modelling, provide the basis for a discussion of the complex flow field and the implications for aircraft safety. Extending Gohm and Mayr's (2005) study of a deep and anticyclonic bora, we find several novel results for a shallow and cyclonic case, and are able to confirm some of the previous findings.

- In accordance with previous studies (e.g. Grubišić, 2004; Jiang and Doyle, 2005; Gohm and Mayr, 2005), the event was characterized by several gap jets and wakes. The most prominent jet formed downstream of the Kapela mountains by the merging of two individual jets in the Kvarner Bay that emanate from two gaps, the Vratnik Pass and the Delnička Vrata. In contrast to the bora case presented in Gohm and Mayr (2005), in which boundary-layer separation was responsible for the wake formation downstream of high terrain, a jet also formed downstream of a gap embedded in the relatively high Velebit mountains. In the present case, gravity-wave breaking near a critical level caused stronger downslope winds, which prevented flow separation to the lee of the Velebit. In Gohm and Mayr (2005), cross-mountain flow was slightly weaker and there was no critical level. Consequently, waves did not overturn; this caused weaker downslope flow that separated from the lee slope.

- Surface-wind observations at Krk Bridge, downstream of the Delnička Vrata gap, suggest that the onset phase of the bora lasted several hours and was characterized by at least three interrupted bora episodes. Intermediate episodes of near-calm conditions were presumably the result of a non-stationary hydraulic jump that was located close to the coast during the whole night but moved back and forth. RAMS did not capture this complex onset behaviour, but placed the time of an abrupt breakthrough at the beginning of the second weak bora episode, characterized by small sustained winds but high gusts. The comparison of simulated surface winds with observations from several weather stations was better for the fully-evolved bora stage, and revealed the strongest sustained surface winds of $10-25 \mathrm{~ms}^{-1}$ near the coast downstream of mountain gaps.

- Measurements with an instrumented car highlighted the evolution of near-surface parameters during the onset phase. The bora front could be detected by a local peak or an increase of potential temperature in the downstream direction. The observed removal of two cold pools in two shallow topographic sinks had already occurred before the bora front passed the island. During the night, near-surface potential temperatures increased along the lee slope between the pass and the island, as a result of downward turbulent mixing of potentially-warmer air in a stably-stratified boundary layer. During the day, near-surface potential temperatures were nearly constant, because of a wellmixed neutral boundary layer. Gravity-wave breaking above the lee slope manifested itself as a decrease in reduced surface pressure along the lee slope of about $6 \mathrm{hPa}$ within a distance of about $20 \mathrm{~km}$, with a local pressure minimum near the coast.

- Apart from minor discrepancies, RAMS is able to correctly reproduce the observed vertical structure of the impinging airflow, which was characterized by an LLJ during the night and a mixed boundary layer topped by a critical level during the day. For the daytime two-layer atmosphere, the Froude-number calculation indicates a subcritical impinging flow, with an upstream Froude number of $F \approx 0.3$, and suggests the transition into a supercritical state at mountain peaks as well as at gaps. This behaviour is supported by the SWM. A sequence of radio-soundings downstream of the coastal barrier reveals the breakthrough of the bora and the passage of a hydraulic jump as a downward shift in time of an elevated inversion that marked the top of the bora flow. Compared with the observed profiles, RAMS appears to predict a breakthrough that is too early and a bora inversion that is too strong and sharp.

- Back-scatter lidar intensities, in combination with the RAMS simulation, document strong descending motions on the leeward side of the barrier, accompanied by low-level acceleration and wave-breaking on top of the bora inversion. The SWM simulation shows that this acceleration resulted in a flow transition into a supercritical state. Furthermore, lidar and RAMS both show gravity waves excited by individual mountain peaks embedded in the larger-scale barrier, with wavelengths of less than $20 \mathrm{~km}$, and indicate damping of vertically-propagating waves by winds that turned with height. The RAMS simulation suggests that the bora flow at Vratnik Pass was approximately twice as 
deep as the flow over the higher Delnička Vrata pass, and did not separate from the lee slope.

- The location of the atmospheric jump predicted by the RAMS model matches the location of the hydraulic jump simulated with the SWM. At the instant shown, the jump was located downstream of the coast in the Vratnik Pass cross-section, and upstream in the Delnička Vrata transect. Furthermore, both models depict the merging of two narrow gap jets into a single broad jet. The peninsula of Istria, as well as the orientation of the Vratnik jet, being non-orthogonal to the mean orientation of the coastal ridge, appear to play an important role in the formation of a single straight jet downstream of Kvarner Bay by promoting flow confluence.

- The RAMS reference simulation agrees well qualitatively with in situ aircraft measurements conducted along a low approach to the airport of Rijeka. Both show strong evidence for wave-breaking on top of the Vratnik jet, the formation of a wave-induced rotor circulation southeast of the airport, and strong crosswinds exceeding $25 \mathrm{~ms}^{-1}$ close to the airport from the Delnička Vrata gap jet. Simulated TKE along the flight path exceeds $8 \mathrm{~m}^{2} \mathrm{~s}^{-2}$ in the rotor and jet-wind regions. Such strongly-varying wind conditions along the flight trajectory, characterized by shifting winds and strong turbulence, represent a potential hazard to aircraft safety. They also present a challenge for forecasters and air-traffic controllers responsible for advising incoming aircraft.

- During the onset phase of the bora, the simulated flow pattern is exceptionally complex at the exit region of the Delnička Vrata gap, and therefore in the vicinity of the airport. At a certain instant, the bora flow through the centre of the gap had advanced further downstream than the flow across the edge of the gap, implying a breakthrough at the gap centre earlier than at the edge. At the gap centre, the descending bora flow rebounded by a hydraulic jump, whereas at the gap edge, boundary-layer separation caused the formation of a rotor circulation underneath a mountain lee wave. The jump was nearly stationary during the night, and started to propagate downstream in the early morning. The rotor started to propagate approximately two hours later. In accordance with Doyle and Durran (2002), the highest TKE values, exceeding $10 \mathrm{~m}^{2} \mathrm{~s}^{-2}$, were found along the upstream edge and near the top of the rotor. The jump was marked by a narrow, verticallyaligned band of high TKE. Lidar observations and model results indicate a downstream propagation of the rotor in the morning of the event.

- The model results are very sensitive to the type of turbulence parametrization used in our simulations. Two closures of LES type, based on isotropic mixing coefficients - a TKE-based scheme in the reference run and a first-order closure in one of the sensitivity runs - exhibit turbulent mixing in the boundary layer that is probably too weak, resulting in a low-level cold bias and an overestimated bora inversion. Furthermore, the bora front propagates too fast, and causes a too-early bora breakthrough. On the other hand, in one of the sensitivity simulations using anisotropic mixing coefficients, the amplitudes of mountain lee waves are strongly underestimated, and the location of the hydraulic jump misplaced, as a result of toostrong horizontal diffusion. Consequently, the bora breakthrough is delayed, relative to observations. The underestimation of the amplitude of trapped gravity waves is supported by back-scatter lidar observations, and was also found in Gohm and Mayr (2005).

- In this case study, we have attributed the formation of a mixed region on top of the bora flow to the mechanism of wave-breaking. At this point, we should note that two fundamentally different mechanisms have been proposed in the literature in order to explain the formation of such a wedge of neutrally-stratified air (see, for example, references on this topic in Mayr et al. (2007)). Measurements of flows over an oceanic sill suggest that this wedge is formed by turbulent mixing due to small-scale shear instabilities (Farmer and Armi, 1999); whereas numerical simulations of the same case support the wave-breaking explanation (Afanasyev and Peltier, 2001). Our model results and observations cannot give a clear answer to this question. We do notice that backward-leaning isentropes are predicted by the model (see, for example, Figures 9(d), $11(\mathrm{c})$ and $15(\mathrm{~b})$ ), causing convective mixing that would be interpreted rather as wave-breaking. On the other hand, high TKE values on top of the downslope flow (see, for example, Figure 12) support shear-induced mixing as the mechanism.

The question remains how far the results of this case study can be transferred to other topographic environments and other events. Idealized numerical simulations, as well as realistic case studies, support several of the phenomena identified here, including jumps, rotors and gap jets. Other phenomena, such as the merging of gap jets, are certainly specific to individual terrain geometries, and cannot be generalized to idealized model terrain without being specifically addressed. Ongoing research conducted in the T-REX framework (Grubišić et al., 2008) provides an excellent opportunity for applying our results to different mountain geometries and background flows.

\section{Acknowledgements}

We would like to thank the Flight Facility and the Lidar Division of the German Aerospace Centre (DLR) for their support in planning and conducting the aircraft mission. We are indebted to our colleagues from the University of Innsbruck, Johannes Vergeiner and Veronika Hawranek, for helping us to realize the field experiment. Many thanks to Stephen Mobbs from the University of Leeds, who provided the mobile radiosounding system. We are grateful to the Meteorological and Hydrological Service of Croatia for making available the Zagreb radio-soundings as well as wind data from 
the station at Krk Bridge. We are indebted to Reinhold Steinacker and Matthias Ratheiser from the University of Vienna for providing VERA data, and to Christoph Schär for providing the SWM code. The Central IT Services (ZID) as well as the High-Performance-Computing (HPC) Consortium of the University of Innsbruck are acknowledged for access to their Linux Compute Clusters, and the Austrian national weather service ZAMG for access to their database. This work was supported by the European Commission through the CAATER Programme 2001 under contract number HPRI-CT-1999-00089, and by the Austrian Science Fund (FWF) under grant P15077.

\section{References}

Afanasyev YD, Peltier WR. 2001. On breaking internal waves over the sill in Knight Inlet. Proc. R. Soc. London A457: 2799-2825.

Arakawa S. 1969. Climatological and dynamical studies on the local strong winds, mainly in Hokkaidō, Japan. Geophys. Mag. 34 $359-425$.

Bajić A. 1991. Application of a "generalized hydraulic theory" to the severe northern Adriatic bora. Meteorol. Rundsch. 44: 129-133.

Belušić D, Klaić ZB. 2004. Estimation of bora wind gusts using a limited area model. Tellus 56A: 296-307.

Belušić D, Klaić ZB. 2006. Mesoscale dynamics, structure and predictability of a severe Adriatic bora case. Meteorol. Z. 15: $157-168$.

Belušić D, Pasarić M, Orlić M. 2004. Quasi-periodic bora gusts related to the structure of the troposphere. Q. J. R. Meteorol. Soc. 130: $1103-1121$.

Carney TQ, Bedard AJ, Brown JM, McGinley J, Lindholm T, Kraus MJ. 1996. Hazardous Mountain Winds and their Visual Indicators. NOAA: Boulder, CO.

Cesini D, Morelli S, Parmiggiani F. 2004. Analysis of an intense bora event in the Adriatic area. Nat. Hazard. Earth Sys. 4: 323-337.

Clark TL, Hall WD, Kerr RM, Middleton D, Radke L, Ralph FM, Neiman PJ, Levinson D. 2000. Origins of aircraft-damaging clear-air turbulence during the 9 December 1992 Colorado downslope windstorm: Numerical simulations and comparison with observations. J. Atmos. Sci. 57: 1105-1131.

Cotton WR, Pielke RA, Walko RL, Liston GE, Tremback CJ, Jiang H, McAnelly RL, Harrington JY, Nicholls ME, Carrio GG, McFadden JP. 2002. RAMS 2001: Current status and future directions. Meteorol. Atmos. Phys. 82: 5-29.

Darby LS, Poulos GS. 2006. The evolution of lee-wave-rotor activity in the lee of Pike's Peak under the influence of a cold frontal passage: Implications for aircraft safety. Mon. Weather Rev. 134: 2857-2876.

De Wekker SFJ, Steyn DG, Fast JD, Rotach MW, Zhong S. 2005. The performance of RAMS in representing the convective boundary layer structure in a very steep valley. Environ. Fluid Mech. 5: 35-62.

Deardorff JW. 1980. Stratocumulus-capped mixed layers derived from a three-dimensional model. Boundary-Layer Meteorol. 18: 497-527.

Defant F. 1951. 'Local winds'. In Compendium of Meteorology, Malone TF (ed). American Meteorological Society Pp. 655-672.

Dorman CE, Carniel S, Cavaleri L, Sclavo M, Chiggiato J, Doyle J, Haack T, Pullen J, Grbec B, Vilibić I, Janeković I, Lee C, Malačič V, Orlić M, Paschini E, Russo A, Signell RP. 2006. February 2003 marine atmospheric conditions and the bora over the northern Adriatic. J. Geophys. Res. 111: C03S03. DOI: $10.1029 / 2005$ JC003134.

Doyle JD, Durran DR. 2002. The dynamics of mountain-wave-induced rotors. J. Atmos. Sci. 59: 186-201.

Doyle JD, Durran DR. 2007. Rotor and subrotor dynamics in the lee of three dimensional terrain. J. Atmos. Sci. 64: 4202-4221.

Drobinski P, Steinacker R, Richner H, Baumann-Stanzer K, Beffrey G, Benech B, Berger H, Chimani B, Dabas A, Dorninger M, Dürr B, Flamant C, Frioud M, Furger M, Gröhn I, Gubser S, Gutermann T, Häberli C, Häller-Scharnhorst E, Jaubert G, Lothon M, Mitev V, Pechinger U, Piringer M, Ratheiser M, Ruffieux D, Seiz G, Spatzierer M, Tschannett S, Vogt S, Werner R, Zängl G. 2007. Föhn in the Rhine Valley during MAP: A review of its multiscale dynamics in complex valley geometry. Q. J. R. Meteorol. Soc. 133: 897-916.
Farmer D, Armi L. 1999. Stratified flow over topography: the role of small-scale entrainment and mixing in flow establishment. Proc. $R$. Soc. London A455: 3221-3258.

FSF. 1993. US report: No conclusive evidence found to explain Boeing 737 crash. Accident Prevention, May 1993: 1-6.

FSF. 1999. Unaware of strong crosswind, Fokker crew loses control of aircraft on landing. Accident Prevention, November 1999: 1-6.

FSF. 2000. Crew fails to compute crosswind component, Boeing 757 nosewheel collapses on landing. Accident Prevention, March 2000: $1-8$.

Gohm A, Mayr GJ. 2004. Hydraulic aspects of föhn winds in an Alpine valley. $Q$. J. R. Meteorol. Soc. 130: 449-480.

Gohm A, Mayr GJ. 2005. Numerical and observational case-study of a deep Adriatic bora. O. J. R. Meteorol. Soc. 131: 1363-1392.

Grubišić V. 1989. Application of the hydraulic theory in cases of bora with strong upstream flow. Rasprave-Papers 24: 21-27.

Grubišić V. 2004. Bora-driven potential vorticity banners over the Adriatic. Q. J. R. Meteorol. Soc. 130: 2571-2603.

Grubišić V, Lewis JM. 2004. Sierra Wave Project revisited: 50 years later. Bull. Am. Meteorol. Soc. 85: 1127-1142.

Grubišić V, Orlić M. 2007. Early observations of rotor clouds by Andrija Mohorovičić. Bull. Am. Meteorol. Soc. 88: 693-700.

Grubišić V, Doyle JD, Kuettner J, Mobbs S, Smith RB, Whiteman CD, Dirks R, Czyzyk S, Cohn SA, Vosper S, Weissmann M, Haimov S, de Wekker S, Pan L, Chow FK. 2008. The Terrain-induced Rotor Experiment: An overview of the field campaign and some highlights of special observations. Bull. Am. Meteorol. Soc. in press.

Helfand HM, Labraga JC. 1988. Design of a nonsingular level 2.5 second-order closure model for the prediction of atmospheric turbulence. J. Atmos. Sci. 45: 113-132.

Hertenstein RF, Kuettner JP. 2005. Rotor types associated with steep lee topography: Influence of the wind profile. Tellus 57A: 117-135. Hill GE. 1974. Factors controlling the size and spacing of cumulus clouds as revealed by numerical experiments. J. Atmos. Sci. 31: 646-673.

Jiang Q, Doyle JD. 2005. Wave breaking induced surface wakes and jets observed during a bora event. Geophys. Res. Lett. 32: L17807. DOI:10.1029/2005GL022398.

Jiang Q, Doyle JD, Wang S, Smith RB. 2007. On boundary layer separation in the lee of mesoscale topography. J. Atmos. Sci. 64: 401-420.

Jurčec V, Glasnović D. 1991. Application of the hydraulic theory to naturally occurring bora flow. Croat. Meteorol. J. 26: 19-40.

Khatwa R, Helmreich RL. 1999. Analysis of critical factors during approach and landing in accidents and normal flight. Flight Safety Digest, November 1998-February 1999: 1-77.

Klemp JB, Durran DR. 1987. Numerical modelling of bora winds. Meteorol. Atmos. Phys. 36: 215-227.

Kraljević L, Grisogono B. 2006. Sea-surface temperature effects on 3D bora-like flow. Meteorol. Z. 15: 169-177.

Kuzmić M, Janeković I, Book JW, Martin PJ, Doyle JD. 2006. Modeling the northern Adriatic double-gyre response to intense bora wind: A revisit. J. Geophys. Res. 111: C03S13. DOI: $10.1029 / 2005$ JC003377.

Lee CM, Askari F, Book J, Carniel S, Cushman-Roisin B, Dorman C, Doyle JD, Flamant P, Harris CK, Jones BH, Kuzmić M, Martin P, Ogston A, Orlić M, Perkins H, Poulain P-M, Pullen J, Russo A, Sherwood C, Signell RP, Thaler D. 2005. Northern Adriatic response to a wintertime bora wind event. EOS Trans. AGU 86: 157-168.

Lilly DK. 1962. On the numerical simulation of buoyant convection. Tellus 14: 148-172.

Long RR. 1954. Some aspects of the flow of stratified fluids. II: Experiments with a two-fluid system. Tellus 6: 97-115.

Louis JF, Tiedtke M, Geleyn JF. 1982. 'A short history of the operational PBL-parameterization at ECMWF'. In Workshop on Planetary Boundary Layer Parameterization. ECMWF: Reading, UK, Pp. 59-79.

Mayr GJ, Vergeiner J, Gohm A. 2002. An automobile platform for the measurement of foehn and gap flows. J. Atmos. Oceanic Technol. 19: $1545-1556$.

Mayr GJ, Armi L, Gohm A, Zängl G, Durran DR, Flamant C, Gaberšek S, Mobbs S, Ross A, Weissmann M. 2007. Gap flows: Results from the Mesoscale Alpine Programme. Q. J. R. Meteorol. Soc. 133: 881-896.

Mellor GL, Yamada T. 1974. A hierarchy of turbulence closure models for planetary boundary layers. J. Atmos. Sci. 31: 1791-1806.

Mellor GL, Yamada T. 1982. Development of a turbulence closure model for geophysical fluid problems. Rev. Geophys. Space Phys. 20: $851-875$. 
Mobbs SD, Vosper SB, Sheridan PF, Cardoso R, Burton RR, Arnold SJ, Hill MK, Horlacher V, Gadian AM. 2005. Observations of downslope winds and rotors in the Falkland Islands. $Q . J . R$. Meteorol. Soc. 131: 329-351.

Mörl P, Reinhardt ME, Renger W, Schellhase R. 1981. The use of the airborne LIDAR system "ALEX F1" for aerosol tracing in the lower troposphere. Contrib. Atmos. Phys. 54: 401-410.

Pan F, Smith RB. 1999. Gap winds and wakes: SAR observations and numerical simulations. J. Atmos. Sci. 56: 905-923.

Pielke RA, Cotton WR, Walko RL, Tremback CJ, Lyons WA, Grasso LD, Nicholls ME, Moran MD, Wesley DA, Lee TJ, Copeland JH. 1992. A comprehensive meteorological modeling system - RAMS. Meteorol. Atmos. Phys. 49: 69-91.

Pullen J, Doyle JD, Haack T, Dorman C, Signell RP, Lee CM. 2007. Bora event variability and the role of air-sea feedback. J. Geophys. Res. 112: C03S18. DOI:10.1029/2006JC003726.

Pullen J, Doyle JD, Hodur R, Ogston A, Book JW, Perkins H, Signell R. 2003. Coupled ocean-atmosphere nested modeling of the Adriatic Sea during winter and spring 2001. J. Geophys. Res. 108(C10): 3320. DOI:10.1029/2003JC001780.

Pullen J, Doyle JD, Signell RP. 2006. Two-way air-sea coupling: A study of the Adriatic. Mon. Weather Rev. 134: 1465-1483.

Ralph FM, Neiman PJ, Keller TL, Levinson D, Fedor L. 1997. Observations, simulations, and analysis of nonstationary trapped lee waves. J. Atmos. Sci. 54: 1308-1333.

Schär C, Smith RB. 1993. Shallow-water flow past isolated topography. I: Vorticity production and wake formation. J. Atmos. Sci. 50: $1373-1400$.

Sheridan PF, Vosper SB. 2006a. A flow regime diagram for forecasting lee waves, rotors and downslope winds. Meteorol. Appl. 13: $179-195$.

Sheridan PF, Vosper SB. 2006b. Numerical simulations of rotors, hydraulic jumps and eddy shedding in the Falkland Islands. Atmos. Sci. Lett. 6: 211-218.
Shutts G. 1995. Gravity-wave drag parametrization over complex terrain: The effect of critical-level absorption in directional windshear. Q. J. R. Meteorol. Soc. 121: 1005-1021.

Smagorinsky J. 1963. General circulation experiments with the primitive equations. I: The basic experiment. Mon. Weather Rev. 91: 99-164.

Smith RB. 1987. Aerial observations of the Yugoslavian bora. J. Atmos Sci. 44: 269-297.

Steinacker R, Häberli C, Pöttschacher W. 2000. A transparent method for the analysis and quality evaluation of irregularly distributed and noisy observational data. Mon. Weather Rev. 128: 2303-2316.

Vergeiner J. 2004. South Foehn Studies and a New Foehn Classification Scheme in the Wipp and Inn Valley. PhD thesis, University of Innsbruck.

Vosper SB. 2004. Inversion effects on mountain lee waves. $Q$. J. R. Meteorol. Soc. 130: 1723-1748.

Vosper SB, Sheridan PF, Brown AR. 2006. Flow separation and rotor formation beneath two-dimensional trapped lee waves. $Q . J . R$. Meteorol. Soc. 132: 2415-2438.

Walko RL, Band LE, Baron J, Kittel TGF, Lammers R, Lee TJ, Ojima D, Pielke RA, Taylor C, Tague C, Tremback CJ, Vidale PL. 2000. Coupled atmosphere-biophysics-hydrology models for environmental modeling. J. Atmos. Sci. 39: 931-944.

Weitkamp C. 2005. Lidar: Range - resolved optimal remote sensing of the atmosphere. Vol. 455, Springer.

Zängl G, Gohm A. 2006. Small-scale dynamics of the south foehn in the lower Wipp Valley. Meteorol. Atmos. Phys. 93: 79-95.

Zängl G, Gohm A, Obleitner F. 2008. The impact of the PBL scheme and the vertical distribution of model layers on simulations of Alpine foehn. Meteorol. Atmos. Phys. in press. 